\title{
ANN-based dynamic control and energy management of inverter and battery in a grid-tied hybrid renewable power system fed through switched Z-source converter
}

\author{
B. Kavya Santhoshi ${ }^{1} \cdot$ K. Mohanasundaram ${ }^{1}$ [D L. Ashok Kumar ${ }^{2}$
}

Received: 11 August 2020 / Accepted: 29 January 2021 / Published online: 17 February 2021

(c) The Author(s), under exclusive licence to Springer-Verlag GmbH, DE part of Springer Nature 2021

\begin{abstract}
The multidimensional purposes of grid-tied hybrid renewable system such as tracking of maximum power, increasing the power conversion efficiency, reducing the harmonic distortions in the injected current and control over power injected into the grid are presented in this paper by developing a laboratory-scale setup. To ensure continuous current operation at the shoot through mode of grid connected inverter, a switched Z-source converter is utilized at the PV side. The PWM rectifier connected with the wind turbine transforms AC power into dc. Individual power converters with conventional PI controllers have been dedicated for each power source, and control strategy uses only one reference voltage so as to increase the maximum power tracking speed from both PV and wind sources. The battery energy management is performed by artificial neural network (ANN) to enhance the stable power flow and increase the lifespan of the storage system. Finally, the voltage at the point of common coupling is fed to ANN-based space vector-modulated three-phase inverter and the converted $\mathrm{AC}$ power is injected to the grid. The overall system performance is measured by estimating the quality of injected power. A stable operation of the proposed microgrid system is verified by varying input and load at the grid. A continuous-time simulation model is realized in MATLAB and is validated using experimental prototype. This benchmark system provides various research scopes for the future smart grids.
\end{abstract}

Keywords PV-wind-battery system $\cdot$ Switched Z-source converter $\cdot$ DC link voltage $\cdot$ PI-fuzzy-ANN controllers $\cdot$ Energy management

\section{Introduction}

With the continuous increase in power demand due to the ever-increasing population, the power generation and distribution unit suffers from overburden and stress. To mitigate these, renewable energy came into existence by which a reliable and continuous power generation is promised by implementing microgrids [1,2]. Among the investments in several renewable sources, wind and PV are in the frontline [3]. Around $26 \%$ of power is generated from renewable sources in all over the country in 2018, and by 2050 this production

K. Mohanasundaram

kumohanasundaram@gmail.com

1 Department of EEE, KPR Institute of Engineering and Technology, Coimbatore, Tamil Nadu, India

2 Department of EEE, PSG College of Technology, Coimbatore, Tamil Nadu, India is expected to reach $100 \%$ by which the present global power demand will be made cheaper. Although the COVID-19 pandemic is severely affecting the global economy at higher rate, a significant investment growth has been continuously notified in the power sector. However, the primary issue associated with these renewable resources is its discontinuous nature and by which the reliability gets affected [4]. To compensate for this, a secondary energy storage such as battery backup system has been utilized with inverter; therefore, the flexibility in storing of power is improved when compared with load regulation-based improvement of power quality $[5,6]$.

This distributed power system can be stand-alone or gridassociated system where the portion of the power is utilized by system load and balance power is supplied to the grid only if some additional energy pervades. To enhance the stable power flow and power quality at the grid side, various control methods have been addressed in the literature [7-10]. To satisfy the local load feeding criteria and to maintain 


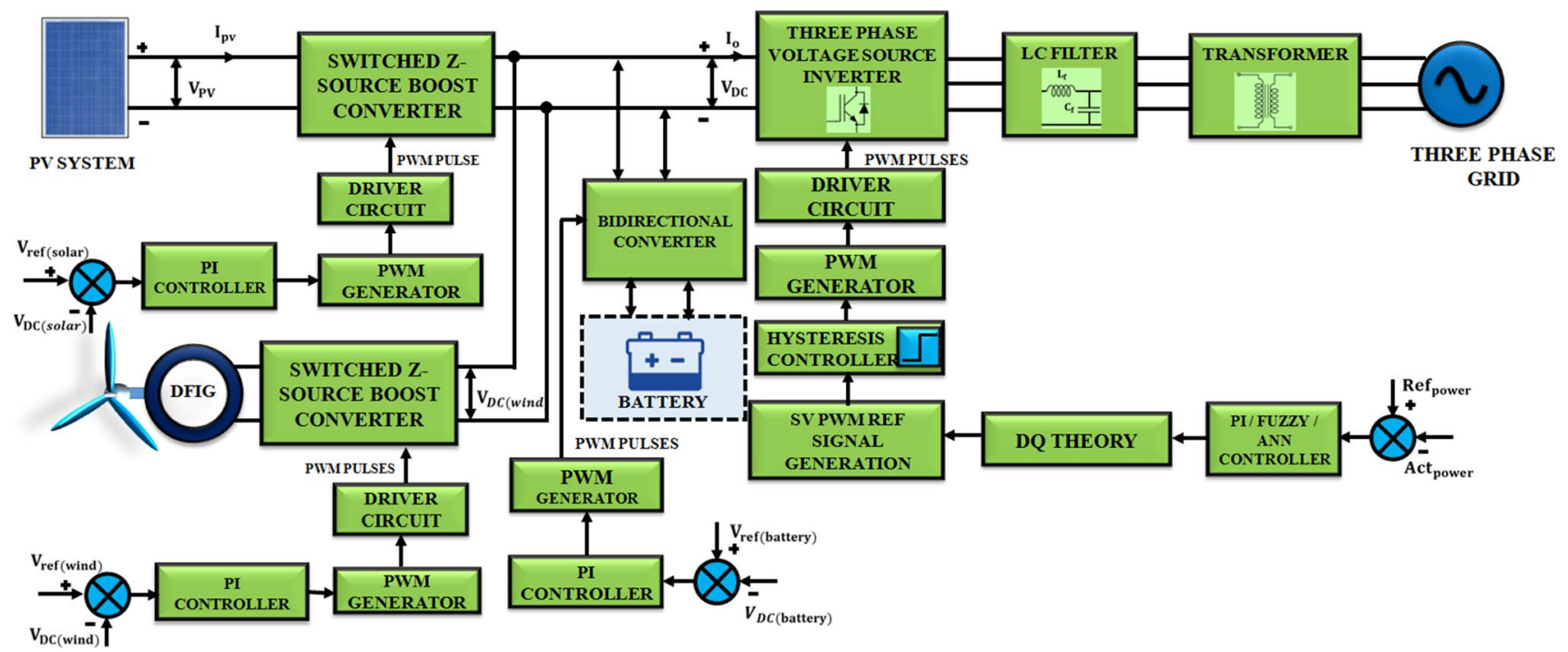

Fig. 1 Diagrammatic representation of proposed system

continuous power supply, grid-connected operation is highly recommended compared to stand-alone operation. Furthermore, there is a necessity that voltage and frequency of grid should be synchronized [11]. The configuration of microgrid is depending on the converter types used in between source and grid. As the outputs of PV and wind are different, converters like DC/DC and AC/DC are employed in addition to inverter for associating the grid with the energy sources. The type of converter to be utilized for a particular system will vary for all systems and is depending on various technical factors, configurations and power ratings [12-15].
As the PV array output is changing with time and of low amplitude, they cannot be applied directly to the inverter connected with grid. There arises a requirement of boost converters so that the panel voltage can be regulated and amplified. Therefore, the proper selection and design of converters is crucial as the system performance is highly relying on the efficiency of the DC-to-DC converters. The boosting ability of step-up converters can be improved using several ways such as cascaded switching technique [16], switched inductance [17], coupled components [18], voltage lift [19] and voltage multiplication [20]. A high voltage

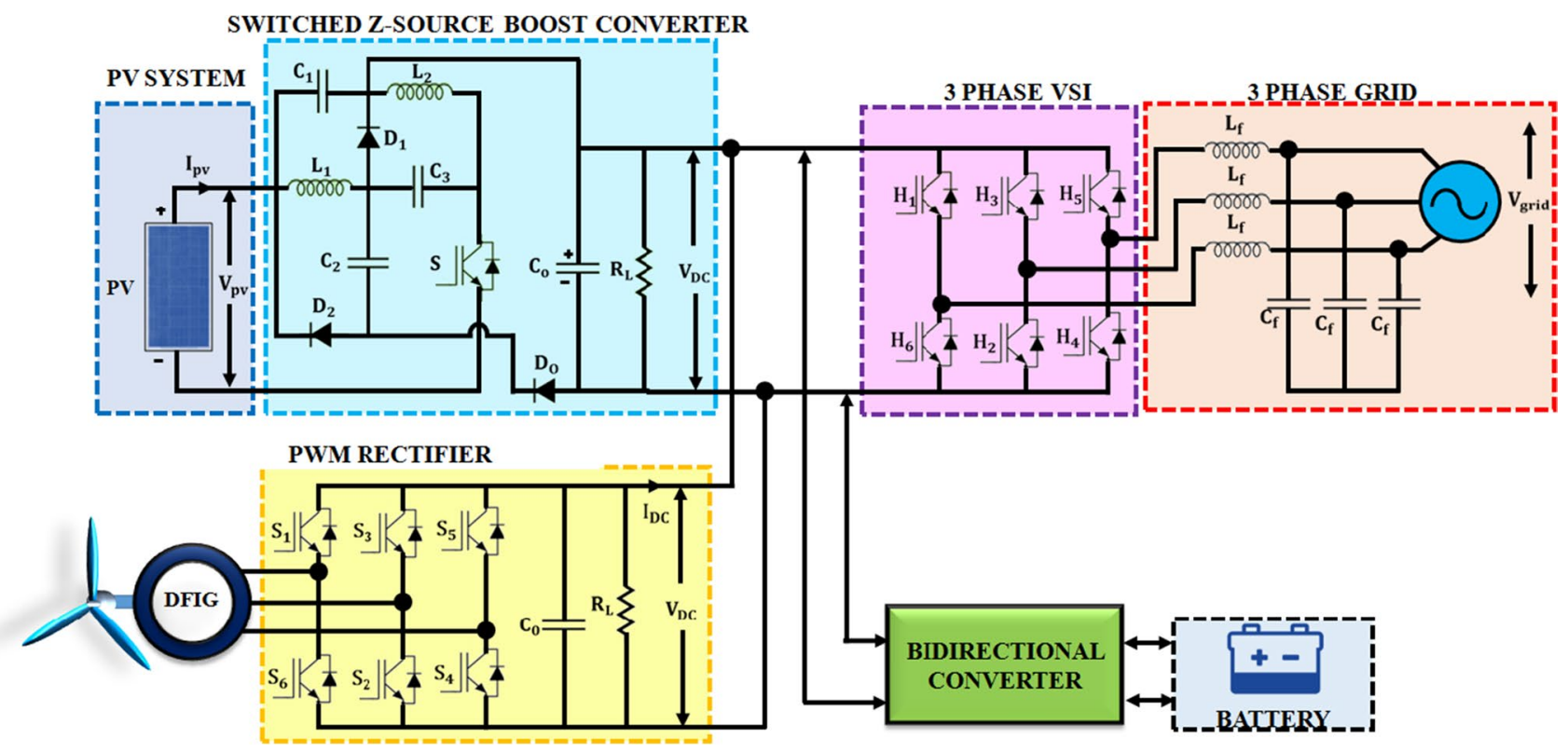

Fig. 2 Diagrammatic representation of overall system 
gain is possible with the above techniques at the cost of high duty cycle and low efficiency. The drawbacks of conventional converters are mitigated by Z-source network which becomes a hot research topic. The Z-source networks utilize the shoot-through mode of inverters to retain the voltage buck inversion capability. The drawbacks of this network such as discontinuous current conduction, limited boosting ability and high voltage stress are overcome by modifying the conventional structure with switched topology which can also be used as a converter, inverter and rectifier [21]. This converter is more suitable for PV application where a converter with high voltage boost is always in demand. The below table justifies the selection of proposed converter in this work.

The control algorithm of maximum power point tracking (MPPT) is executed using either direct duty cycle or closed-loop control. As seen in studies, trial-anderror-based fixed perturbations with constant scaling are required to be initialized in direct duty cycle-based control. But this method results in reduction in tracking efficiency with extended MPP tracking time. To overcome the drawbacks of this adaptive technique, a reference voltagebased closed-loop PI controller can be implemented due to the fact that the MPP voltage difference is comparatively smaller than the difference in MPP current for various insolations [22-25]. Considering the advantages of PI controller and to achieve better control performance over the former adaptive method, a PI controller-based MPPT is adopted for both the converters of PV and wind system. It is essential to operate both the PV and wind system in such a way that they produce maximum power to obtain high efficiency of the proposed system. The above-cited and other existing works concentrate on improving particular section but in this paper each and every module of the grid-connected hybrid renewable systems is presented. Moreover in this paper, automatic control of state of charging of battery is performed using ANN and its

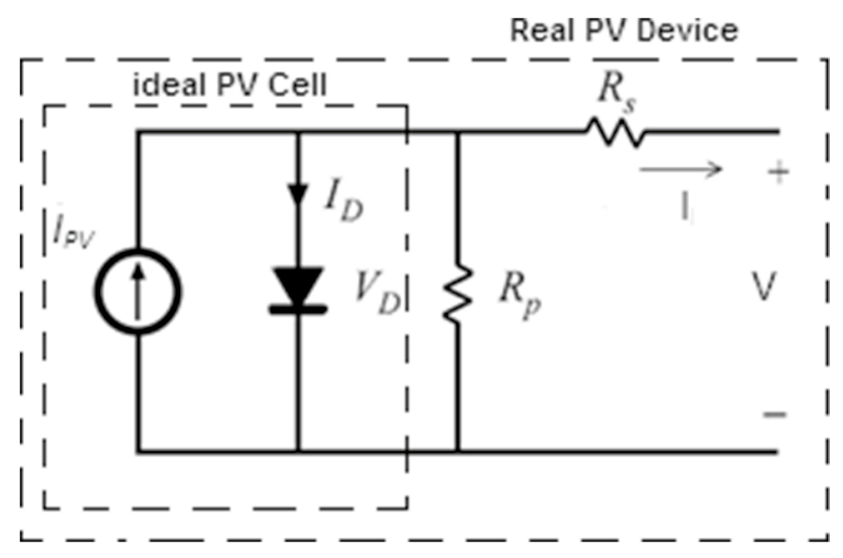

Fig. 3 Electrical circuit performance is compared with artificial intelligence (AI)based fuzzy controller to prove the energy management effectiveness. The developed model provides open testing platform for different control methods.

The contributions of this research work are given below.

- The grid-connected hybrid renewable system is realized by separate voltage source converters and battery backup system so as to inject continuous power to the grid.

- Independent and robust controls of MPPT of the presented renewable sources are performed by simple PI controller.

- A bidirectional converter controlled by ANN controller is employed to maintain constant voltage at the PCC.

- The state-space model of the switched Z-source converter is developed to analyze the system stability, and the simulated effectiveness of the overall system is validated by developing the prototype of the system.

All the above converters and control techniques work only the energy available in PV and wind, respectively. Besides the variation in available energy during daytime and wind blowing period, there may be some time that both the sources fail to produce power. To avoid such nonavailability of power, a battery backup is implemented in the grid-connected system. A smart dispatch system is required to control the power dispatch from battery unit [26]. As the loads connected with the grid are uncertain and are liable to vary, conventional battery management scheme cannot be utilized to manage power flow among the battery and grid. The existing controllers supply the entire power of the battery to the grid if the load value increases and the battery may drain out completely. If this process continues, the battery lifespan minimized which in turn causes power outage and reduces the reliability of entire system. Thus, it is essential to implement smart controllers for efficient management of battery system [27-30]. The outputs of converters of PV and wind sources and battery are connected at the common coupling point where a steady DC voltage is maintained the proposed system. This voltage is coupled to the grid via $3 \Phi$ voltage source inverter (VSI) and filter circuits. As multilevel inverter $[31,32]$ and z-source inverter $[33,34]$ employment makes the circuit complex and costly and reduces the system efficiency, a conventional VSI with LC filter is implemented in our system. Moreover, hybrid system facilitates continuity in power flow, thereby improving the reliability $[35,36]$ (Fig. 1). 


\section{Proposed system}

Figure 2 shows the hybrid energy setup with its converter and control system. The power source consists of an array of PV panels, a wind generator and a storage battery and power-conditioning converters to standardize the power output from the sources and an inverter to interface the grid and energy sources. The PV system is composed of an array of solar panels that are tied up with each other to extract the power output. A switched Z-source converter is implemented to increase the array voltage to a level equal to the DC voltage at the PCC. The wind system has wind blades, a turbine generator and a PWM rectifier to regulate the wind power. A series of batteries is placed to maintain a fixed voltage at the PCC and delivers the power to the grid when there is no output from the renewable sources. The secondary storage system has battery bank and a bidirectional converter that controls the battery's charging and discharging mode via ANN controller. This converter is used as an interface to link the battery terminal and the PCC and controls the flow of current when the voltage levels at the PCC and battery terminal are different. The gridinterfaced inverter delivers the DC power generated from the hybrid resources into the grid as alternating power. A supervisory control scheme is implemented for the inverter and battery and closed-loop PI controllers are dedicated for renewable system, which all together form a hybrid power control and management system. The supervisorycontrol system consists of artificial intelligence-enabled neural and fuzzy networks to coordinate the dynamic and steady power flow.

\subsection{Modeling of PV system}

The PV system converts light energy into electric energy without polluting the environment. A PV cell is the essential component in PV array, which can be resembled as a pn junction diode. The electrical circuit of PV system shown in Fig. 3 is composed of a current source (photocurrent) connected in parallel with a diode, a series resistor to describe the current flow and a shunt resistor to express a leakage current.

The current delivered out from the PV array is expressed as

$I=I_{\mathrm{PV}}-I_{0}\left[\exp \left(\frac{V+I R_{\mathrm{S}}}{\alpha V_{\mathrm{T}}}\right)-1\right]-\left(\frac{V+I R_{\mathrm{S}}}{R_{\mathrm{P}}}\right)$

The equation which relates the voltage and current is given below

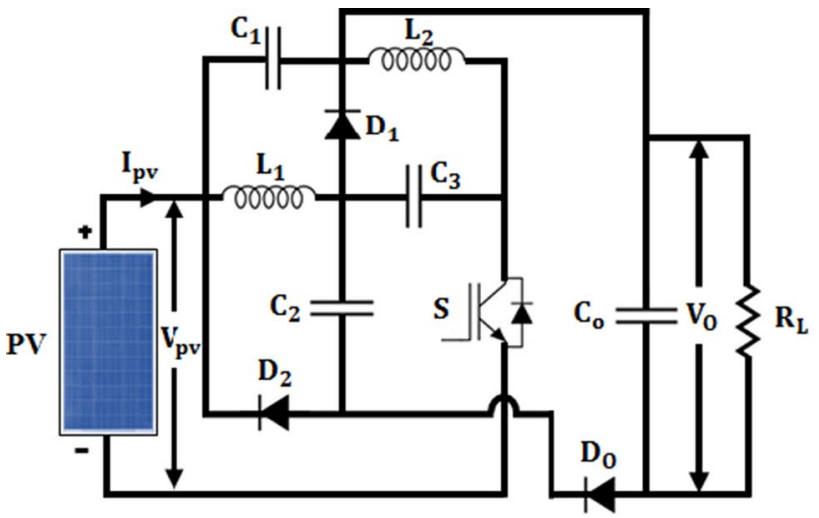

(a) Switched Z-Source Converter

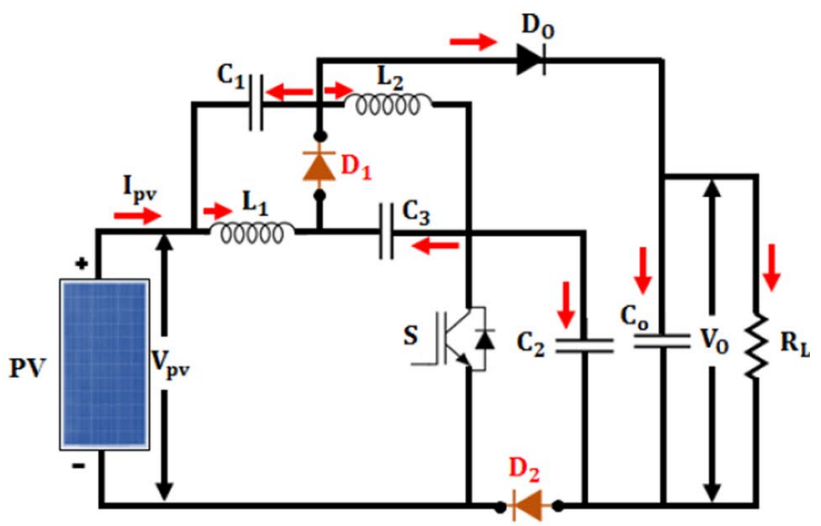

(b) Mode I

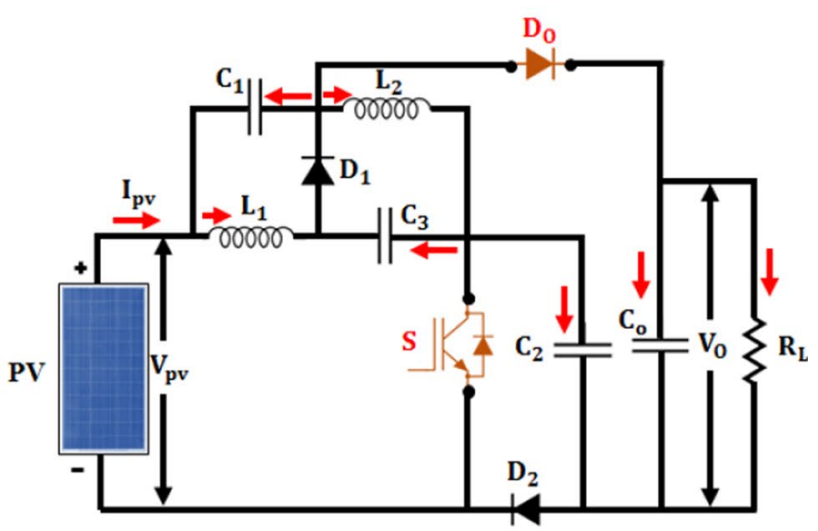

(c) Mode II

Fig. 4 Switched Z-source converter. a Mode I. b Mode II

$V_{\mathrm{PV}}=n_{\mathrm{S}} \frac{A K T}{q} \ln \left\{\frac{n_{\mathrm{p}} I_{\mathrm{SC}}-I_{\mathrm{PV}}+n_{\mathrm{p}} I_{\mathrm{o}}}{n_{\mathrm{p}} I_{\mathrm{o}}}\right\}-\frac{n_{\mathrm{s}}}{n_{\mathrm{p}}} I_{\mathrm{PV}} R_{\mathrm{S}}$

where $V_{\mathrm{PV}}$ and $I_{\mathrm{PV}}$ are the voltage and current output of the PV. $R_{\mathrm{S}}$ is the series resistor; $q$ is the electron charge; $I_{\mathrm{SC}}$ is the short-circuit current; $I_{\mathrm{o}}$ is reverse saturation current; 


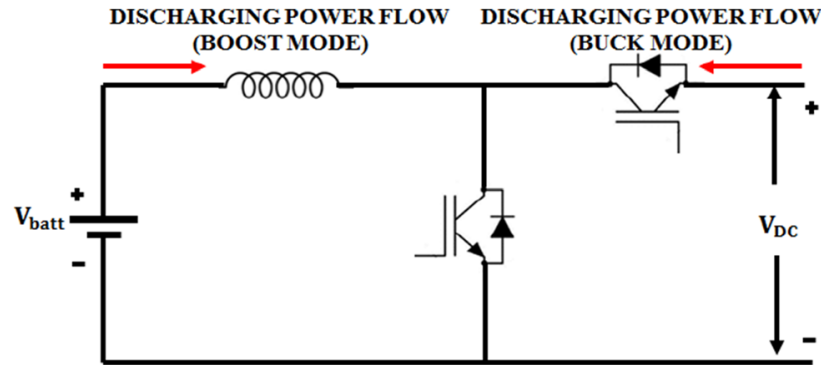

Fig. 5 Bidirectional power flow in battery setup

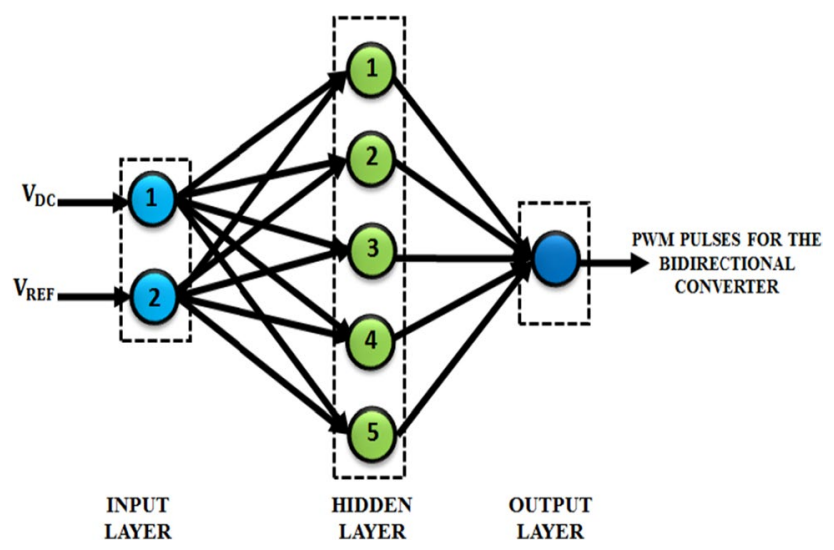

Fig. 6 ANN based control of converter

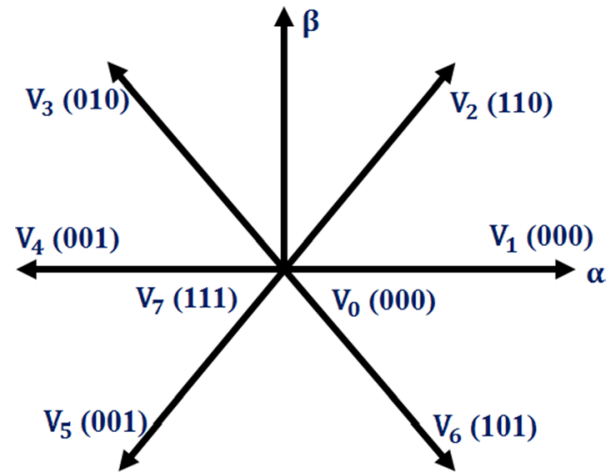

Fig. 7 Space vector representation

$n_{\mathrm{s}}$ and $n_{\mathrm{p}}$ are the number of series- and parallel-connected cells. The PV output power is given by

$P_{\mathrm{PV}}=V_{\mathrm{PV}} \cdot I_{\mathrm{PV}}$

The above equations represent the power output of the solar PV array.

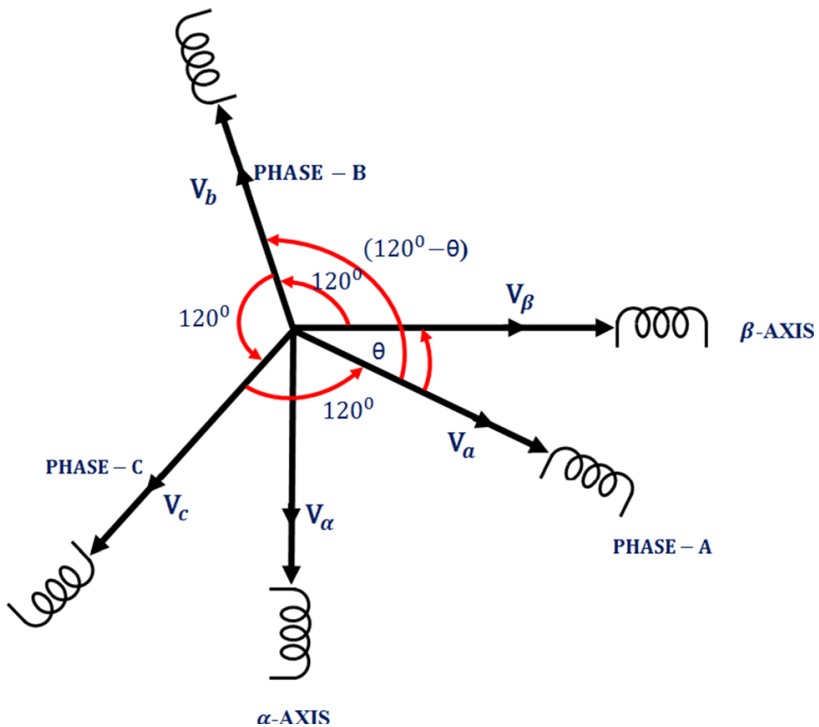

Fig. 8 Transformation of $3 \phi$ to stationary $\alpha \beta$ reference frame

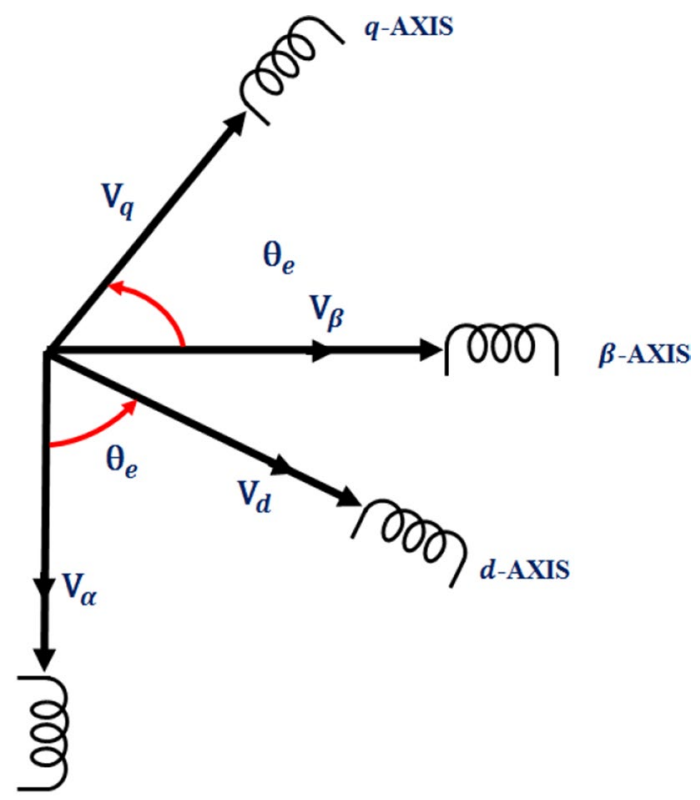

$\alpha$-AXIS

Fig. 9 Relation between stationary and rotating frame

\subsection{Wind turbine design}

The turbine generator transfers the torque produced from the turbine blades to the rotor of the generator by which alternating electrical energy is produced. This generator is associated with a rectifier circuit to give a DC power equivalent to the one generated from the wind system. The rectifier output is controlled to extricate optimum power from the breeze turbine as per the accompanying standards. 

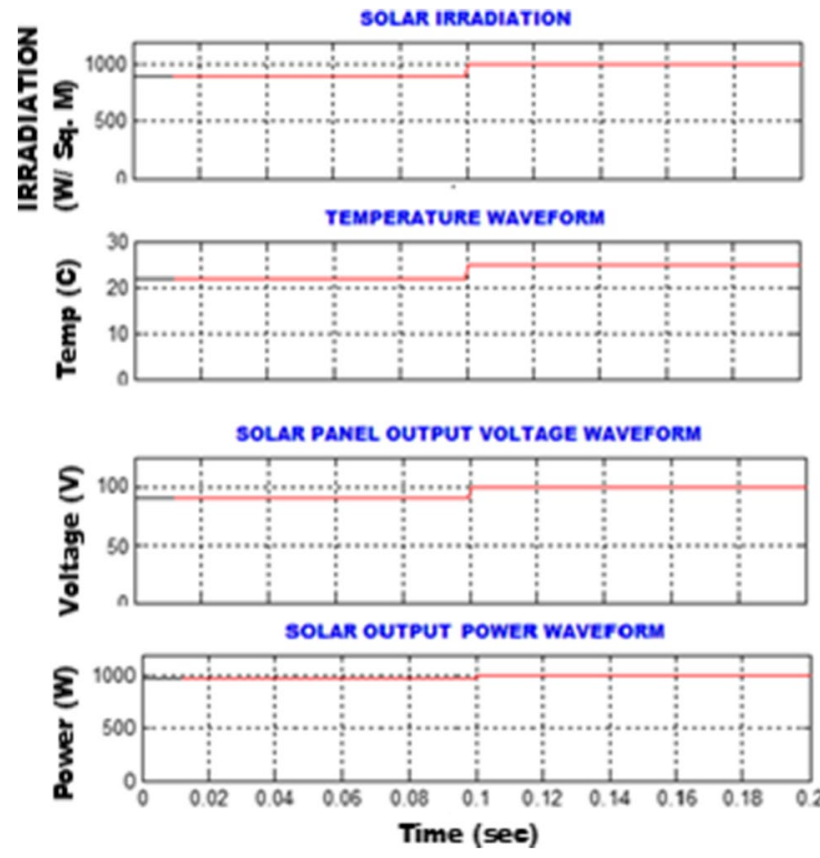

Fig. 10 Solar parameters
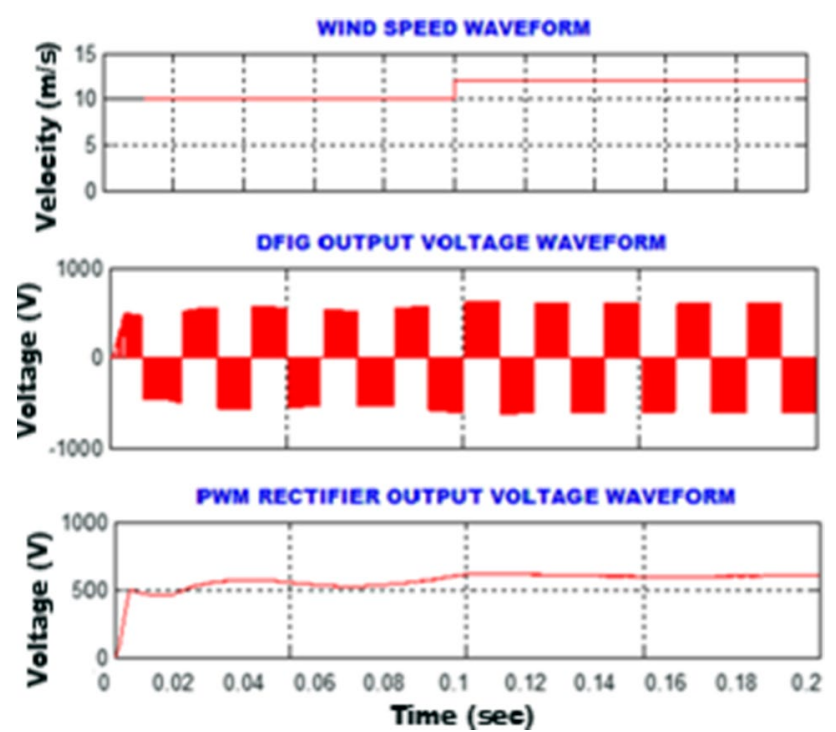

Fig. 11 Output measured at wind turbine side

The basic condition which governs the mechanical power of rotor edges and by which the electrical power is driven is given by

$P=\frac{1}{2} \rho A C_{P} V^{3}$

where $\rho$ is the density of air $\left(\mathrm{kg} / \mathrm{m}^{3}\right), A$ is the territory covered by the blades of the turbine $\left(\mathrm{m}^{2}\right), V$ is the velocity of wind $(\mathrm{m} / \mathrm{s})$ and $C_{\mathrm{p}}$ is the coefficient of power. Consequently, if the density of air, the region covered by wind and speed are kept as constant, then the power output will vary with its coefficient. The breeze turbine is typically characterized by its $C_{\mathrm{p}}$-TSR, where the TSR is the tip-speed proportion and is expressed as:

$\mathrm{TSR}=\frac{\omega_{\mathrm{m}} R}{V}$

$R$ and $\omega m$ are the radius or turbine blade and the rotational angular velocity. The maximum value of power coefficient is expressed if the tip-speed ratio value is optimum, TSRopt which brings about maximum efficiency, and thus the maximum power is absorbed by the turbine.

As observed from (5), the maximum power output is varying wind and rotor speeds. As the wind speed is not controlled, the rotor speed ought to be controlled to follow the TSRopt. This is accomplished by implementing a speed control mechanism in the system so that the rotor runs at high speed when wind speed is high and runs at low speed as wind speed lowers. The speed control of the rotor is employed to control and maximize the TSR and the power coefficient.

Using (5), the maximum rotor speed is calculated as

$\omega_{\text {opt }}=\frac{\operatorname{TSR}_{\mathrm{opt}} V}{R}$

Combining Eqs. (4) and (6), the output torque corresponding to maximum power is

$T=\frac{1}{2} \frac{\rho A C_{\mathrm{P} \max }}{\omega_{\mathrm{opt}}}\left\{\frac{R \omega_{\mathrm{opt}}}{\mathrm{TSR}_{\mathrm{opt}}}\right\}^{3}$

\subsection{Proposed switched Z-source (SZS) converter}

The idea behind the proposed converter is to use a capacitor switch (C2, D2) and combined with another capacitor switch branch $(\mathrm{C} 1, \mathrm{D} 1)$ in the conventional $\mathrm{Z}$-source converter to produce a switched-capacitor cell $(\mathrm{C} 1, \mathrm{C} 2, \mathrm{D} 1, \mathrm{D} 2)$. With this combination, the proposed converter conducts continuous current and attains a higher voltage gain.

The following two assumptions are made to analyze the steady-state behavior of the SZS converter.

1. The switch S, diodes, load resistance RL, inductance and capacitance are assumed as ideal, and their parasitic effects are omitted.

2. Let $\mathrm{L} 1=\mathrm{L} 2=\mathrm{L}$ and $\mathrm{C} 1=\mathrm{C} 3=\mathrm{C}$ in the Z-source converter, and $\mathrm{C} 1=\mathrm{C} 2=\mathrm{C}$ in the switched-capacitor cell, thus $\mathrm{C} 1=\mathrm{C} 2=\mathrm{C} 3=\mathrm{C}$. 
As shown in Fig. 4, two modes of operation are possible when the SZS converter is working in continuous current mode (Figs. 5, 6, 7, 8, 9, 10, 11).

\subsubsection{Mode I}

When switch S is closed, diodes D1 and D2 are opened as they are connected in antiparallel with capacitor. The inductance $\mathrm{L} 1$ charges via $\mathrm{Vi}$ and $\mathrm{C} 3$, and $\mathrm{Vi}$ and $\mathrm{C} 1$ charge $\mathrm{L} 2$. As $\mathrm{Vi}$ and $\mathrm{C} 1$ and $\mathrm{C} 2$ are in series, the load gets supply via switch S. KVL is applied to derive the following steady-state equations:

$V_{\mathrm{L} 1}=V_{i}+V_{\mathrm{C} 3}, V_{\mathrm{L} 2}=V_{i}+V_{\mathrm{C} 1}$ and

$V_{0}=V_{i}+V_{\mathrm{C} 1}+V_{\mathrm{C} 2}$

When S is opened, D1 and D2 are closed, Do is in reverse blocking state, capacitances $\mathrm{C} 1$ and $\mathrm{C} 3$ are charged via $\mathrm{L} 1$ and $\mathrm{L} 2$, and $\mathrm{C} 2$ gets charged as $V_{i}$ and $\mathrm{L} 1$ are in series with L2, and the current flows through the load RL via capacitor Co. The resultant steady-state equations are: $V_{\mathrm{L} 1}+V_{\mathrm{C} 1}=0, V_{\mathrm{L} 2}+V_{\mathrm{C} 3}=0$ and $\mathrm{V}_{\mathrm{i}}=\mathrm{V}_{\mathrm{L} 1}-\mathrm{V}_{\mathrm{C} 3}+\mathrm{V}_{\mathrm{C} 2}$. According to volt-time balance condition of the inductance, the average voltage across the inductance in the steady state is ' 0 .' The duty proportion of switch is defined as, $D=T_{\mathrm{on}} / T_{\mathrm{s}}$, where $T_{\text {on }}$ is the conduction period of switch $S, T_{\mathrm{s}}$ is the total switching time. Thus,

$V_{\mathrm{C} 1}=V_{\mathrm{C} 3}=\frac{D}{1-2 D} V_{i}$

$V_{\mathrm{C} 2}=V_{i}+V_{\mathrm{C} 1}+V_{\mathrm{C} 3}=\frac{2-D}{1-2 D} V_{i}$

From (8) and (9), the output voltage $V_{0}$ can be derived as

$V_{0}=V_{i}+V_{\mathrm{C} 1}+V_{\mathrm{C} 3}=\frac{2-D}{1-2 D} V_{i}$

The gain $(G)$ in voltage of the SZS converter can be obtained as:

$G=\frac{V_{0}}{V_{i}}=\frac{2-D}{1-2 D}$

\subsubsection{Mode II}

In the same sense, as the switch $\mathrm{S}$ is closed in mode II, diodes D1 and D2 get opened, L1 charged via $V_{\mathrm{i}}$ and $\mathrm{C} 3$, and $\mathrm{L} 2$ via $\mathrm{Vi}$ and $\mathrm{C} 1$. Meanwhile, $\mathrm{C} 1$ and $\mathrm{C} 2$ are in series with $\mathrm{Vi}$ and $\mathrm{C} 3$ to provide current for the load. The following equations are obtained by applying KVL.

Those equations are: $V_{\mathrm{L} 1}=V_{i}+V_{\mathrm{C} 3}, V_{\mathrm{L} 2}=V_{i}+V_{\mathrm{C} 1}$ and $V_{0}=V_{i}+V_{\mathrm{C} 1}+V_{\mathrm{C} 2}+V_{\mathrm{C} 3}$ when $\mathrm{S}$ is switched off, $\mathrm{D} 1$ and D2 are turned on, diode Do is reverse blocking, the inductor $\mathrm{L} 1$ charges $\mathrm{C} 1$ and $\mathrm{C} 2$ in parallel, $\mathrm{L} 2$ charges $\mathrm{C} 3$, and the load is powered by capacitor Co. Thus, $V_{\mathrm{L} 1}+V_{\mathrm{C} 1}=0, V_{\mathrm{L} 1}+V_{\mathrm{C} 2}=0$ and $V_{\mathrm{L} 2}+V_{\mathrm{C} 3}=0$.

Using the volt-time balancing condition of inductances L1 and L2, the following equations are obtained:

$V_{\mathrm{C} 1}=V_{\mathrm{C} 2}=V_{\mathrm{C} 3}=\frac{D}{1-2 D} V_{i}$

$V_{0}=V_{i}+V_{\mathrm{C} 1}+V_{\mathrm{C} 2}+V_{\mathrm{C} 3}=\frac{1+D}{1-2 D} V_{i}$

The output voltage gain

$G=\frac{V_{0}}{V_{i}}=\frac{1+D}{1-2 D}$

\subsection{Converter controls}

A variable velocity wind turbine and time-varying PV insolation are utilized. The output of wind system depends on the wind velocity which is then rectified using PWM rectifier and coupled at the PCC.

The operation of SZS converter and rectifier is individually controlled by PI controller whose parameters $K_{\mathrm{p}}$ and $K_{\mathrm{i}}$ are manually tracked to reduce the error voltage $e(t)$ so that the desired performance can be achieved.

The PI controller output $u(t)$ is expressed as,

$u(t)=K_{P} e(t)+K_{i} \int_{0}^{t} e(t) \mathrm{d} t$

By properly varying the parameters of $K_{\mathrm{p}}$ and $K_{\mathrm{i}}$, the controller produces the required reference signal. This reference signal is contrasted with the carrier wave to obtain PWM pulses for switched Z-source converter and PWM rectifier.

\subsection{Modeling of bidirectional converter}

The energy management of the proposed work is performed by battery units and a bidirectional converter so that the potential at PCC will be at the optimum level of $600 \mathrm{~V}$ which is more than the maximum storage capacity of batteries $(540 \mathrm{~V})$. The properly connected low-voltage battery series eliminates the voltage equalization problem found in single-cell battery. Thus, the optimum DC link voltage is maintained at the PCC with increased battery life cycle.

At first the ON time of the pulse period is maintained at $50 \%$ and the converter will neither work in step up nor step down mode and there will not be power stream between battery and grid. The contrast between the PCC voltage amplitude and terminal voltage level of batteries varies the obligation pattern of the converter using the ANN controller. 
At the point when the output of the sustainable sources is beneath the battery voltage level, the bidirectional converter operates in a boost mode and the power from batteries $\mathrm{i}$ extricated to the PCC. Also, when the PCC potential is more than the battery voltage, the converter converts its mode to buck and the power starts to flow from the PCC to battery and thus battery gets charged.

Additionally to decrease the tension at the PCC and to ensure a stable power flow, batteries are included at the PCC. To guarantee ideal planning, it is critical to have precise breeze determining and the information on SOC of the battery. SOC provides the data with respect to how much power available in the battery, and it is depending on inward boundaries, temperature and aging of the batteries. The exact estimation of SOC is yet at research. Among the various techniques to quantify SOC, estimation using ampere hour tallying is utilized in most of the applications. SOC at ' $t$ ' is gotten by utilizing (16) where $Q$ is to the battery limit, $\mathrm{SOC}(0)$ is the underlying $\mathrm{SOC}, I(t)$ is the charging or releasing current of the

$\operatorname{SOC}(t)=\operatorname{SOC}(0)-\frac{1}{Q} \int_{0}^{t} I(t) \mathrm{d} t$

It is necessary to keep up SOC of the battery inside the base and most extreme levels for efficient utilization of battery energy and hence for power booking. The favored degrees of battery activity considered are $20-90 \%$ of SOC.

When the renewable power is not exactly the planned worth, battery gives the rest of the power, and when the power is overabundance than the network request, power is consumed by the battery. Using the ANN controller, the control pulse is produced by contrasting voltage at the PCC with the battery terminal voltage.

\subsection{Controlling of inverter}

The output of three-phase inverter is standardized by maintaining the optimum and phase-synchronized power at the grid side. To extract the reference pulses for the inverter controller, a PI, fuzzy and ANN controllers are considered in this paper.

(i) PI controller: The self-tuning ability, simple construction and easy availability make them suitable for most of the applications. However, they suffer from slow tracking and response delay and inability to deal with stable error.

(ii) Fuzzy controller: The error in power tracking and its derivative are fed as input to the fuzzy controller. The design of fuzzy controller is depending on the awareness, information, skill and exposure of the functional designer. Because of the nonlinearity of the inverters, the controller is insensitive to parameter variation and types of inverter and can operate at stable condition. Among the nonlinear and repetitive controllers, the fuzzy controller is best controller. Solid suppositions and sufficient experience are required in the fuzzification process as it is depending on the system information and makes determina-

Table 2 Specification of the solar panel

\begin{tabular}{ll}
\hline Parameters & Values with unit \\
\hline Peak power $\left(P_{\mathrm{mp}}\right)$ & $100 \mathrm{~W}, 10$ panels \\
Open circuited voltage $\left(V_{\mathrm{oc}}\right)$ & $22.68 \mathrm{~V}$ \\
Short circuited current $\left(I_{\mathrm{sc}}\right)$ & $4.61 \mathrm{~A}$ \\
Peak power voltage $\left(V_{\mathrm{mp}}\right)$ & $18.75 \mathrm{~V}$ \\
Peak power current $\left(I_{\mathrm{mp}}\right)$ & $5.42 \mathrm{~A}$ \\
Number of cells $\left(N_{\mathrm{s}}\right)$ & 36 \\
\hline
\end{tabular}

Table 1 Comparison of components count of different converters

\begin{tabular}{llllll}
\hline Components count & $\begin{array}{l}\text { SB con- } \\
\text { verter [22] }\end{array}$ & $\begin{array}{l}\text { QSB con- } \\
\text { verter [23] }\end{array}$ & $\begin{array}{l}\text { qSZS with } \\
\text { CC [24] }\end{array}$ & $\begin{array}{l}\text { Modified SB } \\
\text { converter [25] }\end{array}$ & $\begin{array}{l}\text { Pro- } \\
\text { posed } \\
\text { current }\end{array}$ \\
\hline Switches & 1 & 1 & 1 & 1 & 1 \\
Inductor & 1 & 1 & 2 & 2 & 2 \\
Capacitor & 1 & 1 & 2 & 2 & 3 \\
Diode & 2 & 2 & 4 & 2 & 2 \\
Boost factor for 0.3 duty cycle & 0.9 & 2.4 & 4.6 & 6.2 & 10 \\
Voltage gain for modulation index .7 & 1.1 & 1.9 & 3.8 & 5.2 & 7.8 \\
Network switch stress & 2 & 0.9 & 1.5 & 1.6 & 1.4 \\
Inductor stress & 1.9 & 1.8 & 1.45 & 1.6 & 1.42 \\
Capacitor stress & 2 & 1.8 & 1.6 & 0.6 & 1.5 \\
Diode stress & 2 & 0.9 & 1.6 & 1.5 & 1.45 \\
\hline
\end{tabular}


Table 3 Performance comparison of conventional PI controller with $\mathrm{P} \& \mathrm{O}$ and fuzzy controller

\begin{tabular}{lllllll}
\hline Controller & $K_{\mathrm{p}}$ & \multicolumn{1}{c}{$K_{\mathrm{I}}$} & $\left(\mathrm{t}_{\mathrm{r}}\right)$ & $\left(\mathrm{t}_{\mathrm{p}}\right)$ & $\left(\mathrm{t}_{\mathrm{s}}\right)$ & $\mathrm{E}_{\mathrm{ss}}$ \\
\hline P\&O method & 0.1974 & 9.5832 & 0.3724 & 0.4357 & 0.5186 & 0.48 \\
Fuzzy controller & 0.2764 & 13.3251 & 0.283 & 0.3677 & 0.3677 & 0.34 \\
PI controller & 0.3765 & 32.1847 & 0.072 & 0.1158 & 0.1578 & 0.13 \\
\hline
\end{tabular}

tions as per the rule set appointed to them during the modeling and designing procedure.

(iii) ANN controller: The ANN controller works like human brain. It has number of artificial neurons that behave as a human brain. The reference tracking error information is given through a suitable scaling factor as input to the ANN to produce the control pulses for the inverter. A constant operating frequency is achieved in both online and offline modes to control the inverter. The functional mapping estimation of ANN controller provides high level of fault tolerance. Knowledge on inverter model is not needed for ANN controller, but, the functional behavior of inverter should be precisely known while designing the ANN controller.

(iv) Space vector modulation: Space vector modulation (SVM) is a regulatory strategy that becomes famous in the control and is generally applied in three-stage network associated inverter. SVM is complimenting best pulse width modulation (PWM) strategy because of the numerous highlights of SVM; for example, SVM can give $20 \%$ higher yield voltage than the sinusoidal PWM.

SVM can be structured as a solitary unit. This unit has eight exchanging levels; each exchanging state depicts the voltage space vector as a point in two-dimensional complex vector planning in $\alpha \beta$. The beneath figure shows the vector hexagonal state of the SVM where the shape is separated in six nonzero changing areas from $\mathrm{V} 1$ to $\mathrm{V} 6$ in which $\mathrm{V} 0$ and $\mathrm{V} 7$ are lining in the inception position of the hexagon.

The control system is dedicated to control the power flow using closed-loop PI controller by which actual grid power is compared with the reference power.

In this control, an LC filter is utilized to synchronize the grid voltage and current. As such, it is significant to control the phase and recurrence of the system. The error between the actual and estimated grid power is given to PI controller whose transfer function is

$G=k_{p}+\frac{k_{i}}{s}$

The output of PI controller serves as a current reference in dq frame.
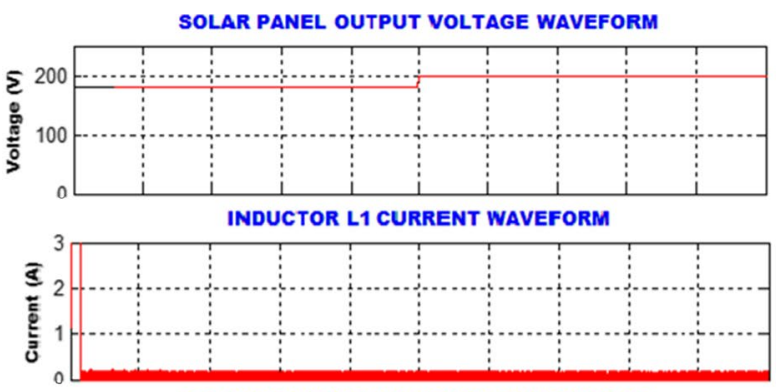

VOLTAGE ACROSS WAVEFORM CAPACITOR C1
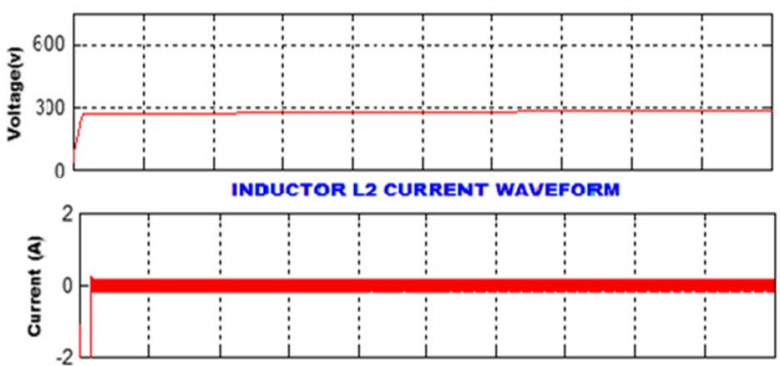

VOLTAGE ACROSS WAVEFORM CAPACITOR C2

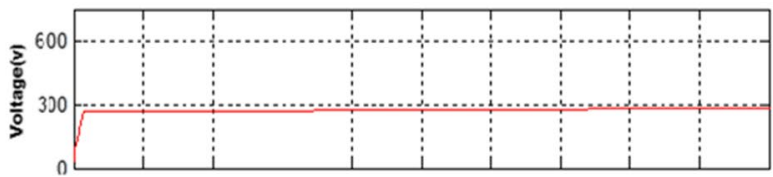

Z SOURCE NETWORK OUTPUT VOLTAGE WAVEFORM

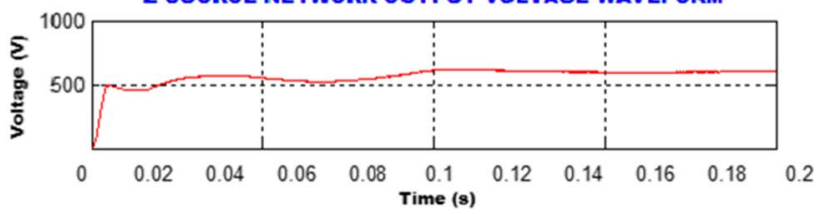

Fig. 12 Output of PI-controlled SZS

Using SVM, the $3 \Phi$ reference voltages $V_{\mathrm{a}}, V_{\mathrm{b}}$, and $V_{\mathrm{a}}$ are transformed into $\alpha \beta$ orthogonal plane using Clarks transformation

$\left[\begin{array}{l}V_{\alpha} \\ V_{\beta} \\ V_{0}\end{array}\right]=\frac{2}{3}\left[\begin{array}{ccc}1 & -0.5 & -0.5 \\ 0 & 0.866 & -0.866 \\ 0.5 & 0.5 & 0.5\end{array}\right] *\left[\begin{array}{c}V_{a} \\ V_{b} \\ V_{c}\end{array}\right]$

Different control techniques are accessible to control the $3 \phi$ inverter associated with grid to enable dynamic power flow. A notable sign model can be utilized in which $3 \phi$ quantity is converted into dq outline (pivoting reference) which is said as Park's transform. 

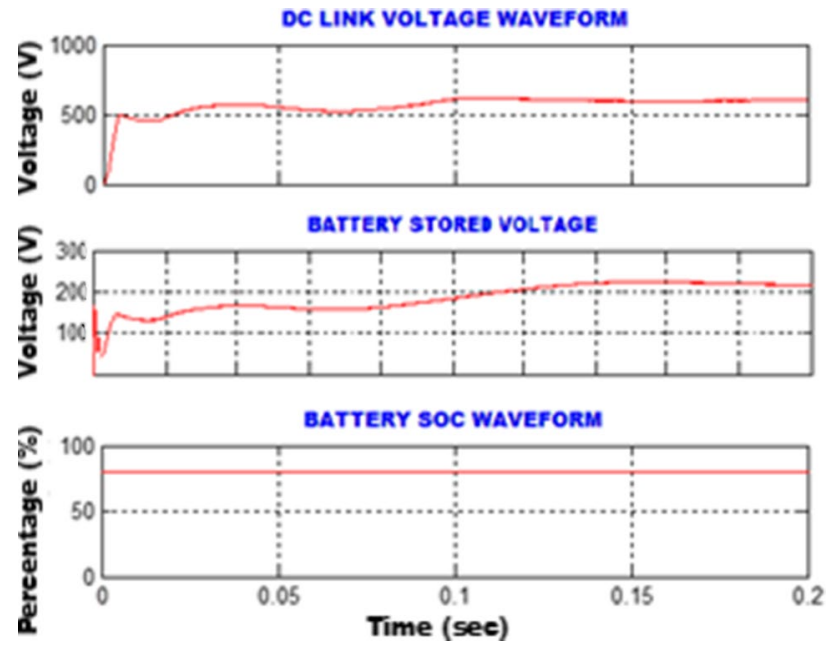

Fig. 13 Voltage at PCC and battery terminal
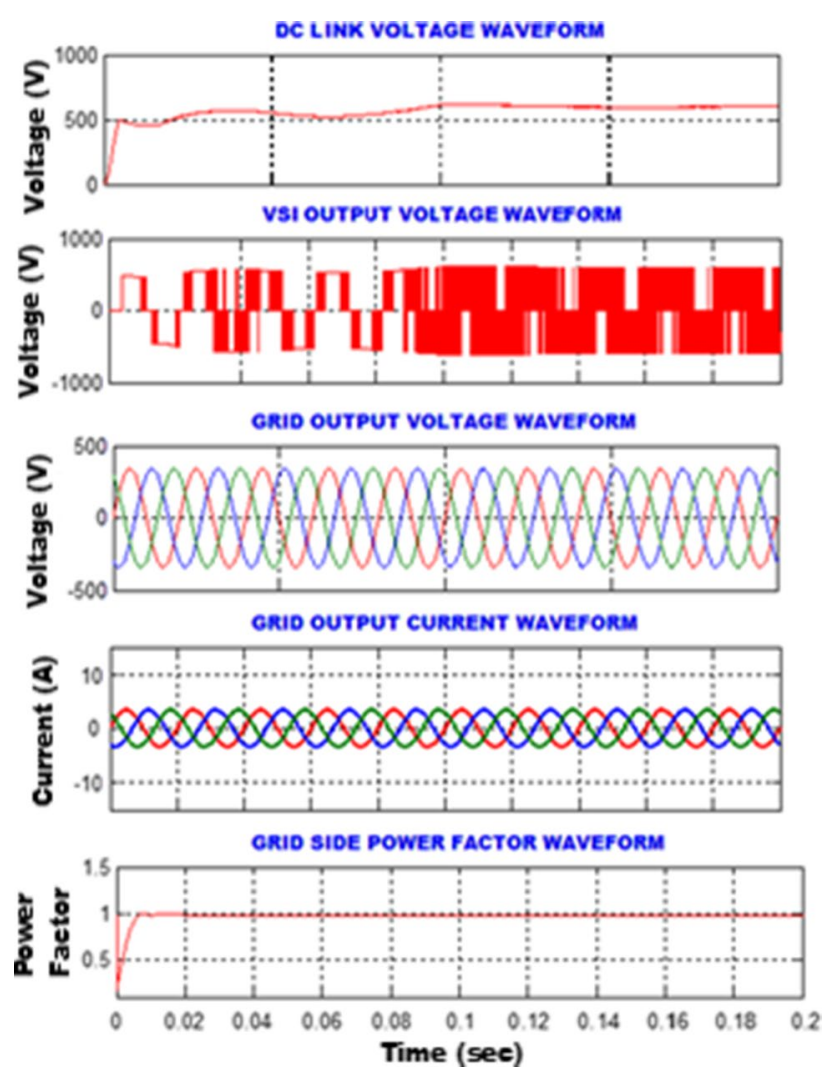

Fig. 14 Output measure at grid side

The $3 \phi$ SVPWM controller gives PWM signals by utilizing Clarke transform where $3 \phi$ vector into $2 \phi$ fixed reference outline segments. The last two parts assume an essential job in producing the PWM signals.

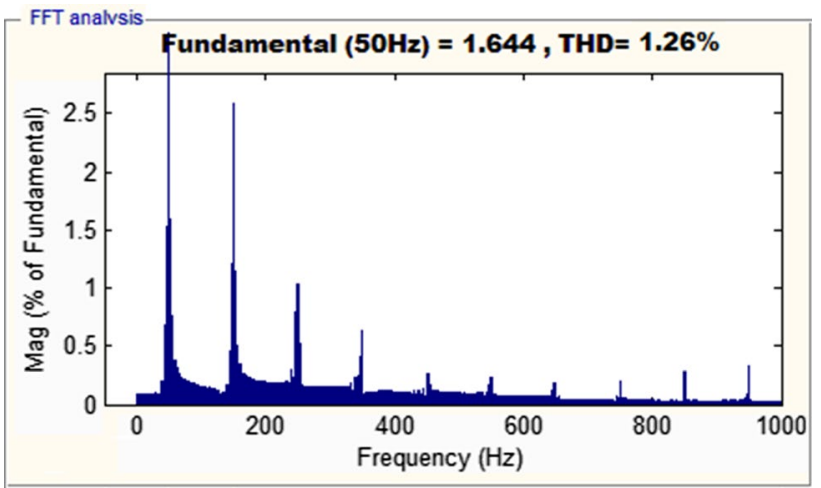

Fig. 15 THD at the grid side

The below matrix equation indicates the Park transform where the stationary vector is transformed into rotating vector.

$\left[\begin{array}{l}V_{d} \\ V_{q}\end{array}\right]=\left[\begin{array}{cc}\cos \theta_{e} & \sin \theta_{e} \\ -\sin \theta_{e} & \cos \theta_{e}\end{array}\right] *\left[\begin{array}{c}V_{\alpha} \\ V_{\beta}\end{array}\right]$

Thus, Clarke transform $(3 \phi-2 \phi)$ transforms three-phase into two-phase stationary reference vector and Park transform changes $2 \phi$ stationary vector into rotating vector. These changes are conceivable to deduce DC control loop for effective tracking of the AC quantities with reduced steady-state errors.

To coordinate the yield current frame to follow the reference frame, the SVM method uses the ideal yield voltage vector esteem. Notwithstanding, the figuring is not down to earth. Thus, the HCC can be used to make the line current frame to track the order vector with practically slow reaction time and lack of care toward the line voltage and boundary variety. Notwithstanding, because of misunderstanding between individual HCC, high exchanging recurrence may happen and the current mistake is not carefully constrained. This issue in the HCC can be understood utilizing the spacevector idea.

\section{Results and discussion}

A periodical scale reproduction arrangement is created for the PV-wind framework in MATLAB to assess and approve the framework execution (Table 1). A $1 \mathrm{KW}$ is picked as the appraisal of the PV-wind generator. The whole models are built utilizing the sim power-framework tool stash. The discrete sort recreation is utilized with an inspecting time of $20 \mathrm{~ms}$. The ratings of PV panels given below are chosen to provide a maximum power of $1000 \mathrm{~W}$. The specifications of the solar panel chosen are given in Table 2. 


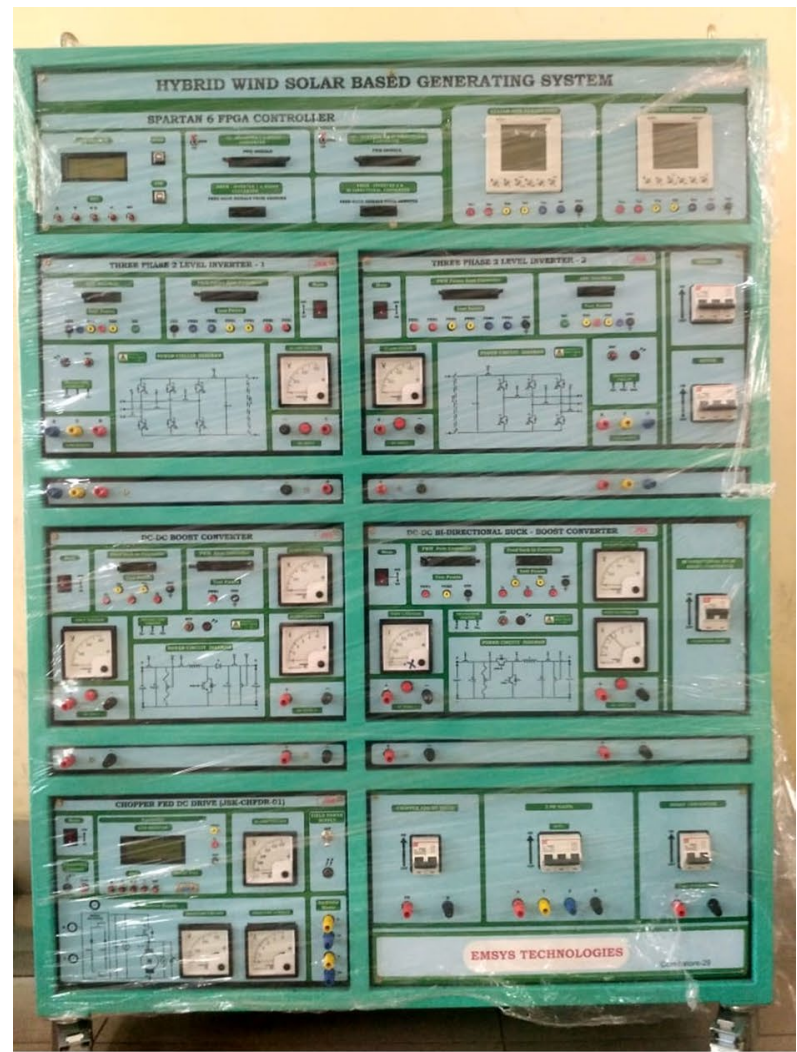

(a) Hardware implementation circuit 2

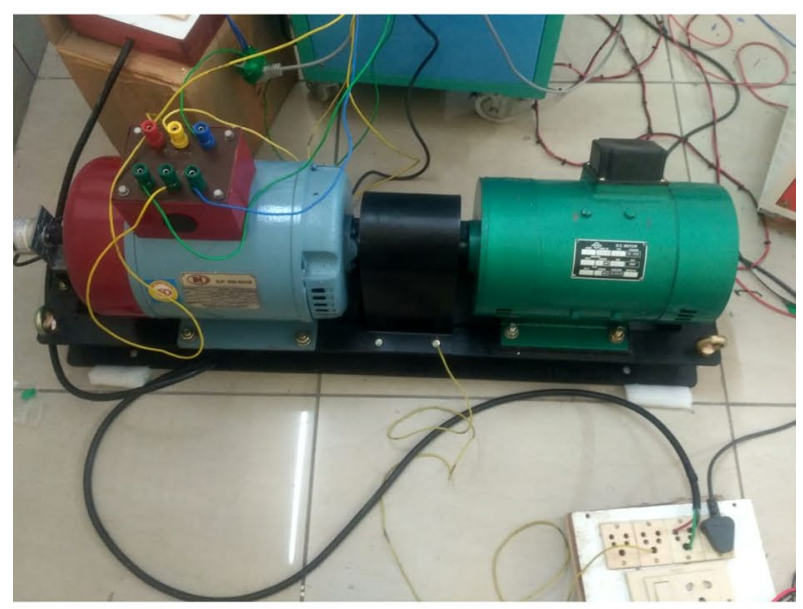

(b) Hardware implementation circuit 3

Fig. 16 a Hardware implementation circuit 2. b Hardware implementation circuit 3

The point of the proposed framework is to give steady power for the grid under a few producing circumstances by utilizing renewable sources (Table 3).

The PV insolation is constrained by changing the temperature and consequently by giving different irradiation levels from $800 \mathrm{~W} / \mathrm{m}^{2}$ to $1000 \mathrm{~W} / \mathrm{m}^{2}$. The breeze speed is

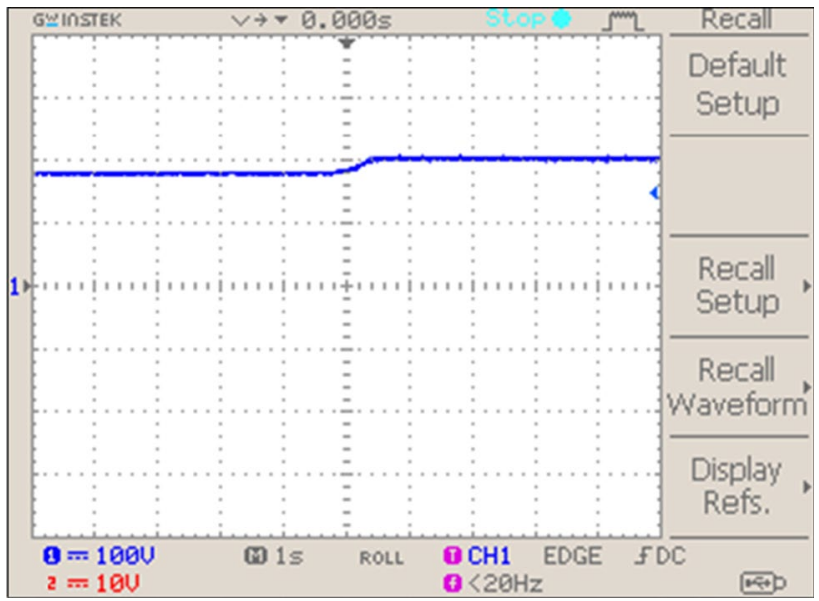

Fig. 17 Solar PV voltage

constrained by varying the speed of the fan blower from $4 \mathrm{~m} / \mathrm{s}$ to $12 \mathrm{~m} / \mathrm{s}$.

\subsection{Design of SZS converter}

The inductor L1, L2 in the SZS converter is calculated by,

$L_{1}, L_{2}=\frac{2 V_{\mathrm{pv}} D(1-D)}{x_{L} \cdot I_{a} f_{\mathrm{sw}}}$

$L_{1}=L_{2}=2.53 \mathrm{mH}$.

The following equation calculates the capacitors $C_{1}, C_{2}$ in the SZS converter,

$C_{1}, C_{2}=\frac{I_{o} D}{x_{\mathrm{C}} \cdot f_{\mathrm{sw}} V_{i}(1-2 D)}$

$C_{1}=C_{2}=2800 \mu \mathrm{F}$.

Around ten quantities of $12 \mathrm{~V}$ batteries are sequentially associated to obtain a yield voltage of $120 \mathrm{~V}$. With the underlying power of $1000 \mathrm{~W}$, the board clusters keep up a normal of $800 \mathrm{~W}$ over the reenactment time.

In spite of the fact that the adjustments in the PV insolation and wind speed are just step variations that never occur in the down to earth because of the changing condition conditions.

The scopes of significant worth are chosen to transform from the usable least and most extreme operational scopes of the PV cluster and wind framework in order to approve the exhibition of the framework for these changes.

Additionally, for this situation, the framework is variable as it would show up in a continuous domain under the 
Fig. 18 a Current through inductor L1 of SZS converter. b Current through inductor L2 of SZS converter. $\mathbf{c}$ Voltage across capacitor C1 of SZS converter. d Voltage across capacitor C2 of SZS converter. e SZS converter output voltage

nonstacking condition in order to quantify the operational exhibition of the force transformation and the battery frameworks for the adjustments in the power delivered by the PV and wind system.

The SZS converter output is shown in Fig. 12. When $V_{\text {in }}=200 \mathrm{~V}$ and duty cycle is 0.35 , the voltages across $C_{1}$ and $C_{2}$ are $300 \mathrm{~V}$, and the output is stepped up to $450 \mathrm{~V}$. When the duty ratio changes to 0.4 , the voltages at the output, $C_{1}$ and $C_{2}$ are $600 \mathrm{~V}, 350 \mathrm{~V}$ and $400 \mathrm{~V}$, and it is noticed from that the output is increased to $600 \mathrm{~V}$ and the voltages across $C_{1}$ and $C_{2}$ are $350 \mathrm{~V}$ and $400 \mathrm{~V}$.

Using the ANN controller, the SOC is balanced effectively and the power is found to be continuously flowing to and from the battery. Initially, the SOC is assumed at $70 \%$. Based on the change in output of PV converter and PWM rectifier, the SOC will get varied. The controller maintains the constant voltage at the PCC within the time period of $0.2 \mathrm{ecs}$ and the battery settles at this voltage. Thus, the controller shows the excellent tracking and learning ability. It is understood that an efficient energy management has been acquired by which a stable PCC voltage is maintained irrespective of change in source variations.

A stable DC link voltage is attained at PCC with fixed amplitude of $600 \mathrm{~V}$, and in addition the nature of the grid current is also preserved with a THD of $1.26 \%$ when ANN controller is used to control inverter and closed-loop PI controller is used for SZS controller. Any problems that exist at any point of the system will get reflected at the grid side in terms of harmonics The value of THD determines the overall performance which includes the conversion efficiency, gain of converters, SOC of battery and effective inverter action of the system connected with grid.

The voltage and current in Fig. 12 and THD analysis result in Fig. 13 indicate the efficient dynamic power flow and energy management of the proposed system (Figs. 14, $15)$.

\subsection{Hardware results}

The FPGA-based laboratory setup of the renewable power system with battery backup is developed to analyze and estimate the attributes of the proposed power conversion system. Figure 16a shows a $1 \mathrm{~kW}$ PV and DFIG system and battery arrangements. The PI controller of PV and wind power has not optimized; instead, just a conventional type is utilized for quick tracking of MPPT. The controller utilizes only PCC voltage as a reference signal and feeds back the control signal using power-conditioning circuits

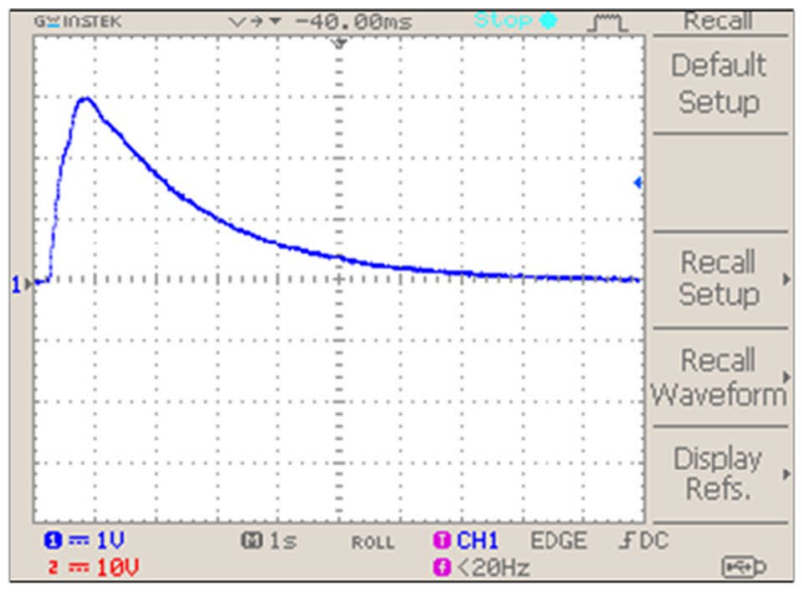

(a). Current through inductor L1 of SZS converter

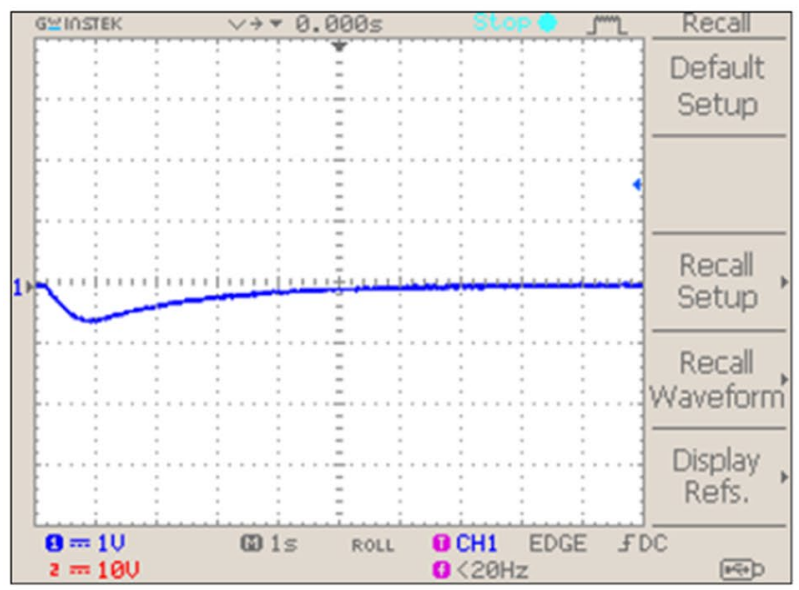

(b). Current through inductor L2 of SZS converter

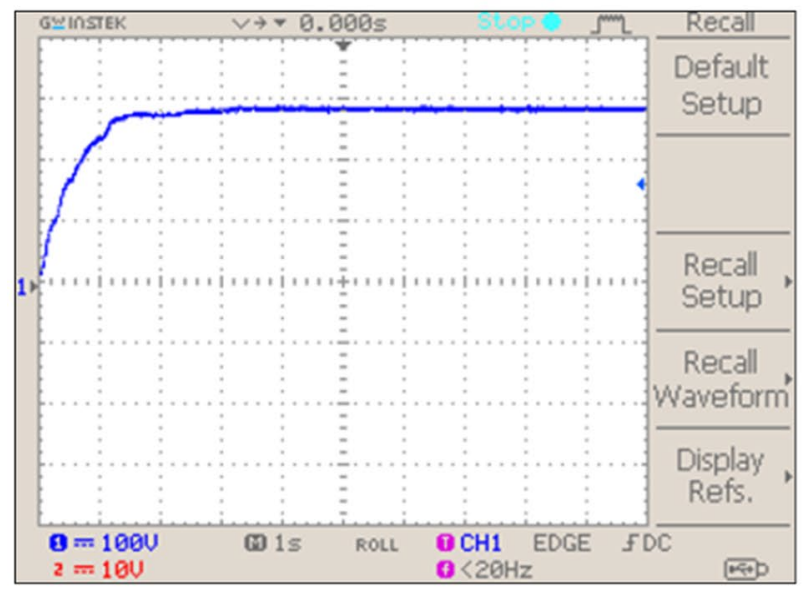

(c). Voltage across Capacitor Cl of SZS Converter 


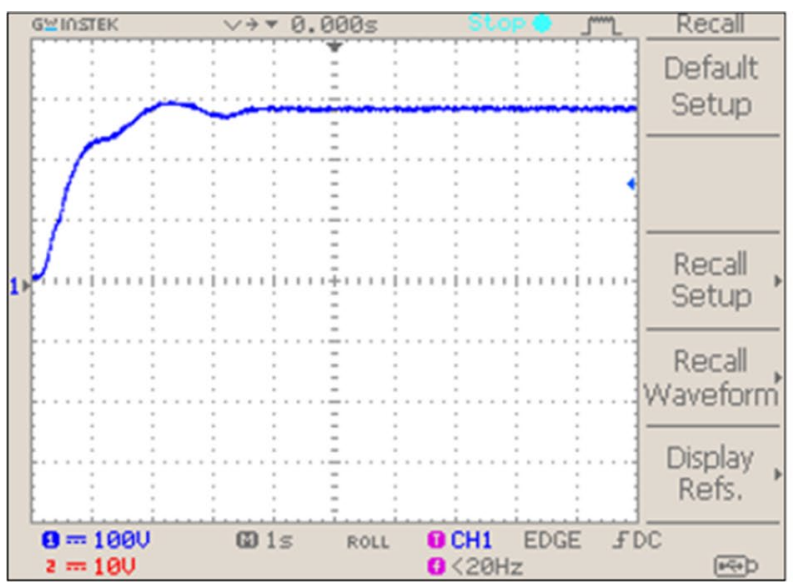

(d). Voltage across Capacitor C2 of SZS Converter

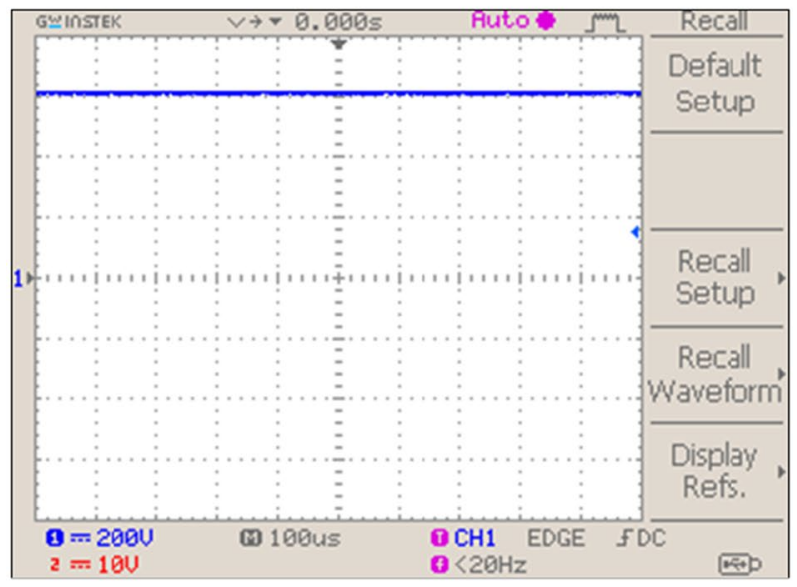

(e). SZS Converter output voltage

Fig. 18 (continued)

via proper filters. Internal PWM modules are needed by the ANN controller to drive the inverter via isolated driver circuit. The input-output connecting pins are utilized to operate the power contactor via EM relay. The total control system is automated using the dsPIC3050 FPGA controller.

The hardware setup of converter needs an inbuilt driver circuits so as to handle the required power-driving capability. For the circuits shown in Fig. 16a, the developed prototype is given below. The wind energy conversion system model is shown in Fig. 16b. A DC shunt motor is a prime mover which generates mechanical energy and coupled with DFIG to produce AC electrical power. This system is just a functional demonstration of the proposed system, and actual experiment will be discussed in the future.

The output of PV panel is varied by varying the irradiance level as shown in Fig. 17. The aim is to deliver constant power irrespective of any change in input and load. The

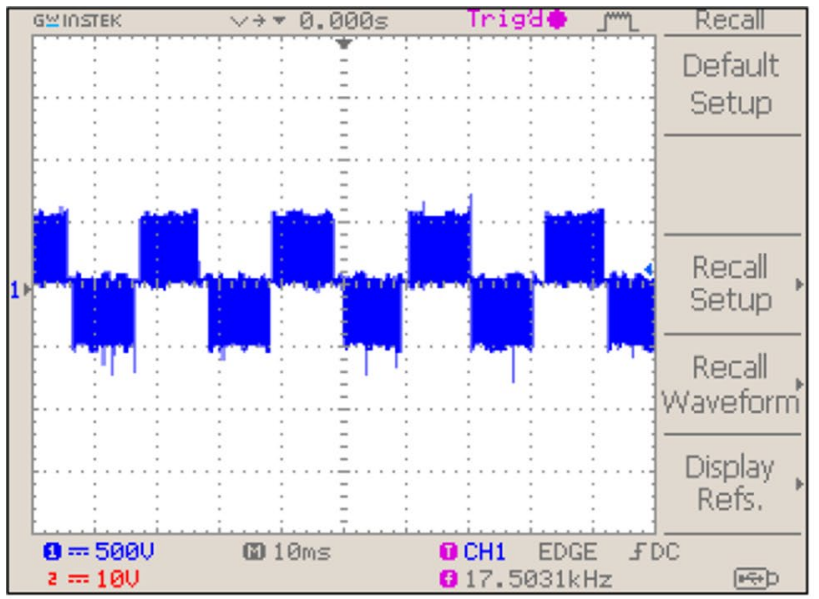

(a). DFIG output voltage

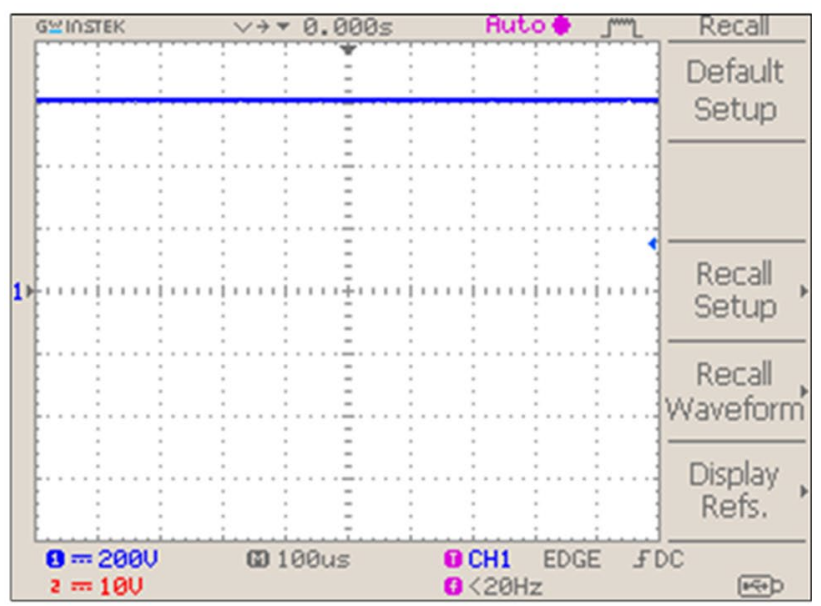

(b). PWM rectifier output

Fig. 19 a DFIG output voltage. b PWM rectifier output

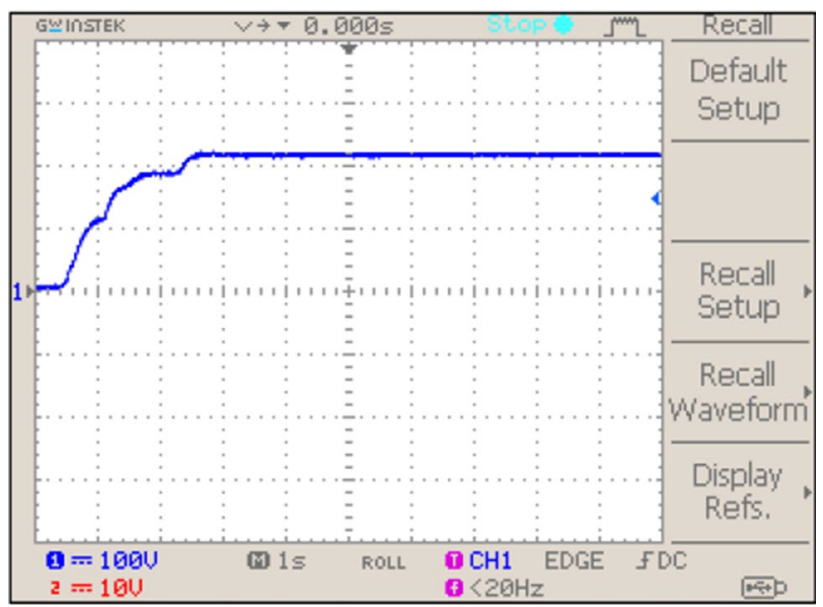

Fig. 20 a Stored voltage in battery 


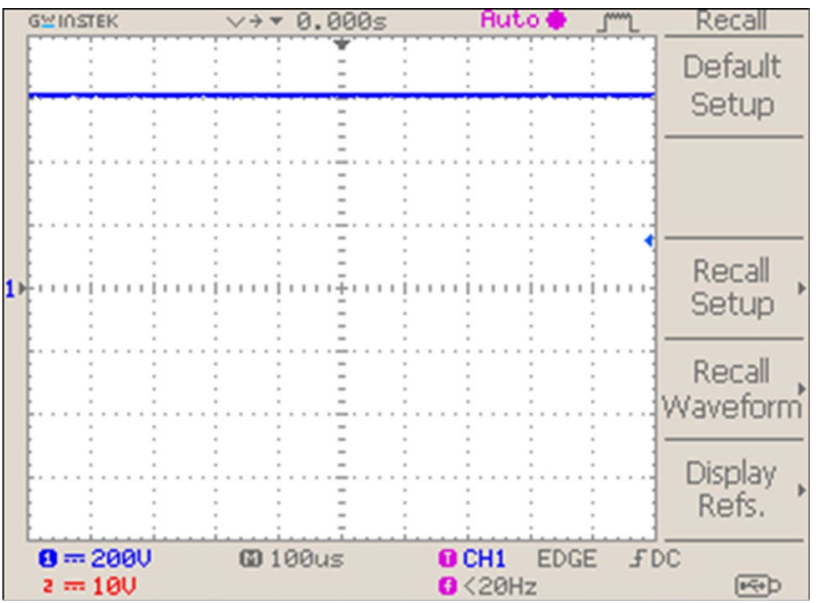

Fig. 21 DC link voltage

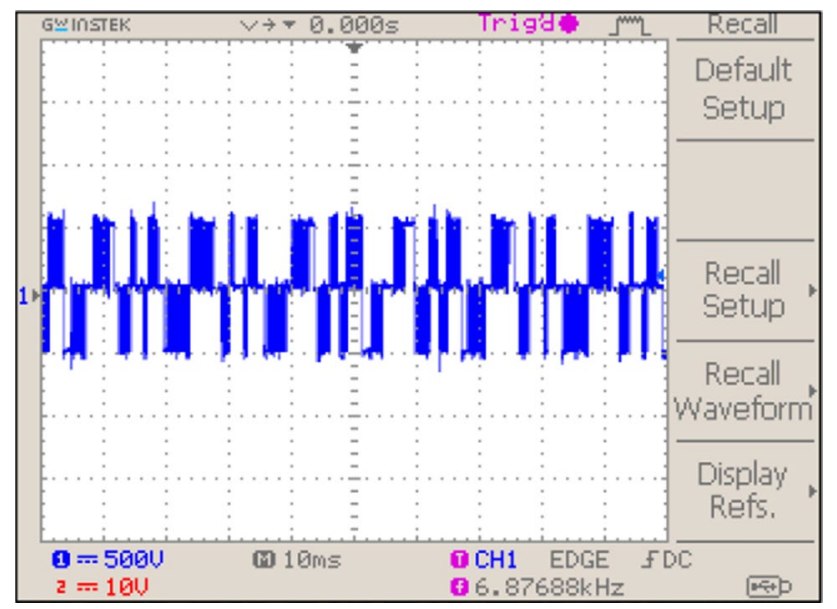

Fig. 22 Output of VSI

required power balance is attained by maintaining the DC link at a constant value.

The current through inductors $L_{1}$ and $L_{2}$ shown in Fig. 18a and $b$ reveals that no energy is stored in converter and hence all the power flowing into the circuit will get forwarded to the next stage.

At the initial time, the current amplitudes are at positive and negative peaks in $L_{1}$ and $L_{2}$ which indicates that charging and discharging are taking place at the same time.

Similarly, the voltage amplitudes at $C_{1}$ and $C_{2}$ of SZS converter shown in Fig. $18 \mathrm{c}$ and d indicate that a fixed voltage is available at the converter output as shown in Fig. 18e.

Thus, with simple PI controller, a fixed voltage is maintained at the converter output (Figs. 19, 20).

The hardware output of PV and wind shows that the performance is not compromised with developed prototype as the simulation results are reflected in the hardware results.
The voltage at the battery terminal is maintained at high level as the power will be available either from any one source, and the SOC is varied based on the magnitude of DC link voltage. This developed model seems to have continuous voltage at the PCC.

Hence, even though there is no output from PV or wind turbine, there will be DC link voltage available at the PCC because of battery setup. The DC link voltage is shown in Fig. 21.

This voltage is fed to inverter and converted into appropriate AC voltage and injected into the grid (Fig. 22).

Using ANN controller, the switches of the inverter are pulsed at different intervals to produce $\mathrm{AC}$ waveform with less THD.

The hardware result of the injected voltage waveform is given in Fig. 23. The grid current is sinusoidal and is in phase with the grid voltage explicitly, which mentions dynamic power flow at the grid. Further, the harmonic content in the grid current shown in Fig. 24 is nearly $2 \%$.

The THD at the grid current is $2.2 \%$ when SVPWM is used by inverter and $3.2 \%$ is acquired with SPWM controller.

It is to be noted that with PI controller, the $t_{\mathrm{r}}$ (rise time), $t_{\mathrm{p}}$ (peak time) and $e_{\mathrm{ss}}$ (steady-state error) are reduced comparatively better than $\mathrm{P} \& \mathrm{O}$ and fuzzy controllers. The objective function is also reduced. The effectiveness of different controllers is compared with the proposed SZS converter. The comparison between different controllers chosen under this work has been tabulated in 3 .

The tracking performance of PI controller is compared with $\mathrm{P} \& \mathrm{O}$ and fuzzy controllers in Fig. 25. For the same environmental conditions and simulation settings, the performance is varied and improved much with PI controller. A maximum efficiency of $98 \%$ is achieved with the proposed controller, and that for fuzzy and $\mathrm{P} \& \mathrm{O}$ is $96.5 \%$ and $90 \%$.

\subsection{SZS converter performance}

Figure 26 represents the comparison of voltage gain of different converters, which indicates that the voltage transfer ratio is linearly varying with duty proportion. The voltage gain attains the peak value with $40 \%$ duty cycle and for the proposed SZS converter is nearly 10 , and those for Landsman and LUO converters are 6 and 3.5 for $40 \%$ duty cycle. As the duty cycle is decreased, the switching losses are decreased but the overall performance of the system is not improved.

\subsection{Inverter side performance}

The comparison of THD for the SVPWM and SPWM is made for the SZS converter controlled by PI controller, fuzzy controller and ANN controller. The SVPWM shows better performance when the inverter is controlled by ANN controller. The graphical representation of this comparison is shown in 


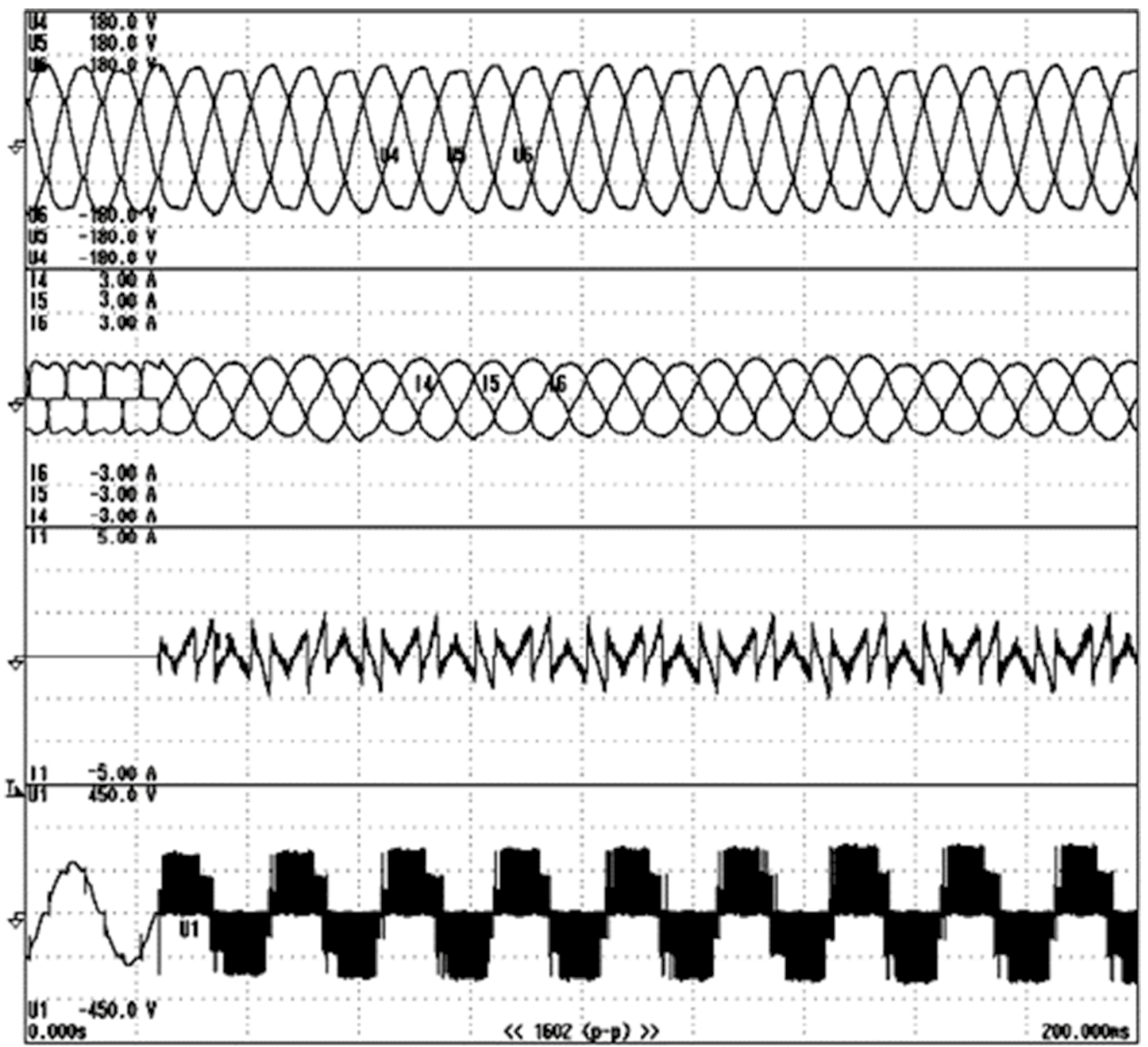

Fig. 23 Voltage injected at the grid

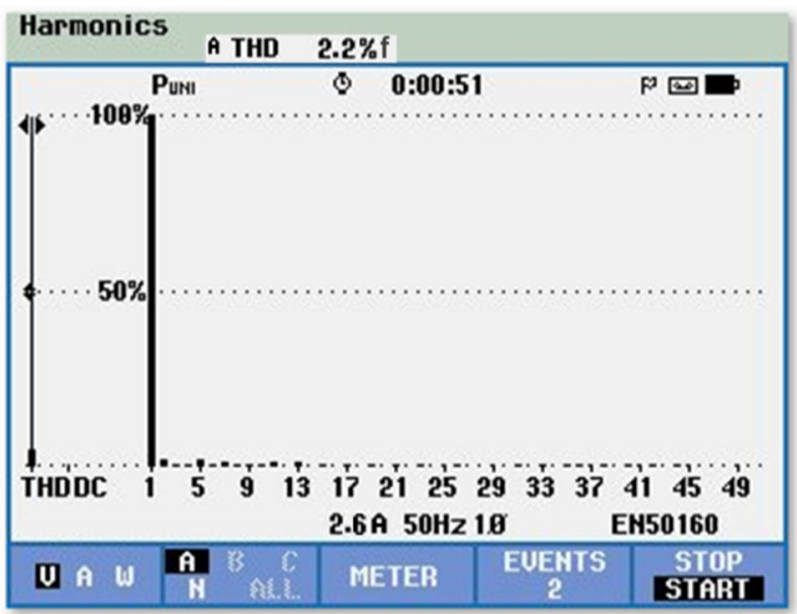

Fig. 24 Grid current THD

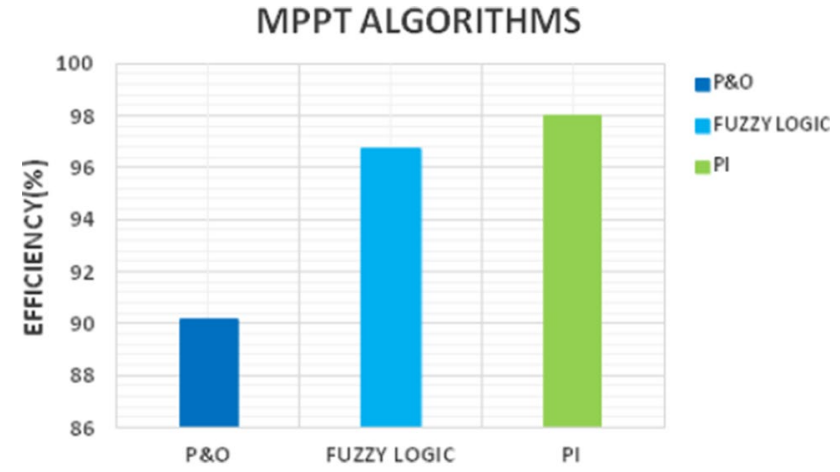

Fig. 25 Comparison of MPPT algorithms

Fig. 27, and the THD values obtained are detailed in Table 4. From Table 4, it is also visible that compared to conventional PI and AI-enabled fuzzy logic controller, ANN controller 


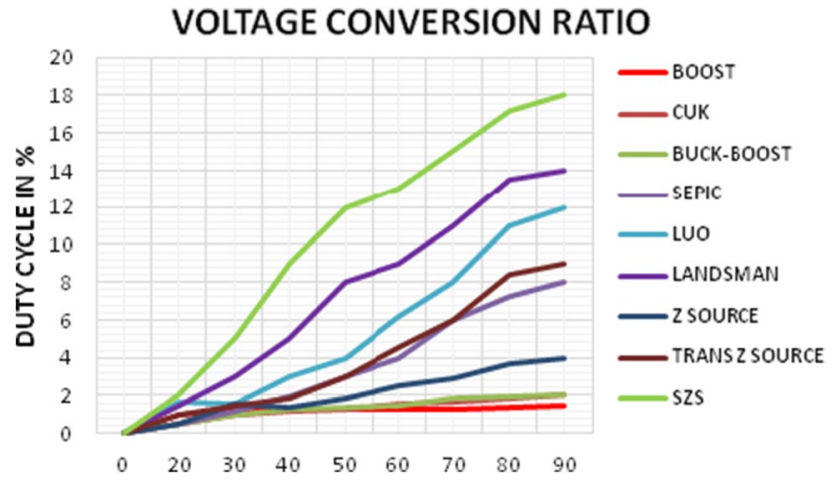

Fig. 26 Voltage conversion ratio

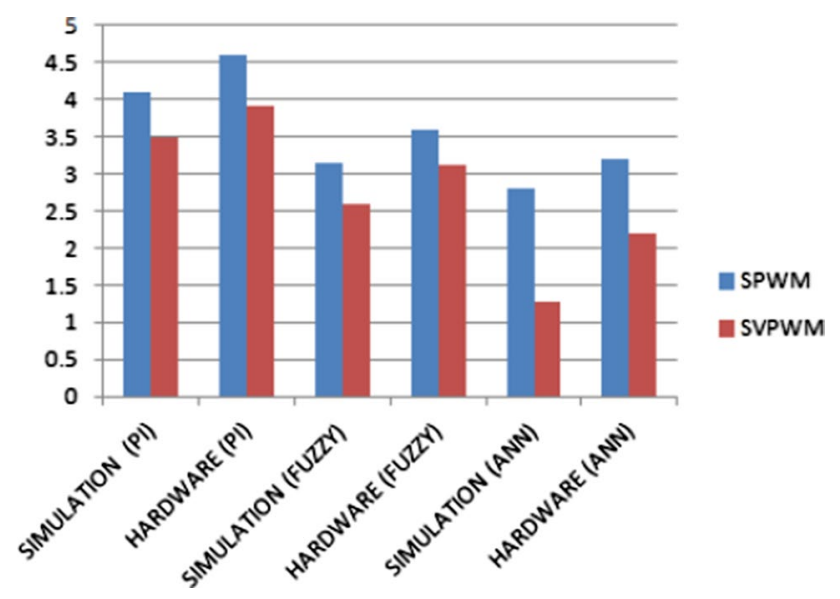

Fig. 27 THD comparison

Table 4 THD comparison of SPWM and SVPWM

\begin{tabular}{|c|c|c|c|c|c|c|}
\hline \multirow[t]{2}{*}{ Method } & \multicolumn{2}{|l|}{ PI } & \multicolumn{2}{|c|}{ Fuzzy } & \multicolumn{2}{|c|}{ ANN } \\
\hline & Sim & $\mathrm{H} / \mathrm{W}$ & Sim & $\mathrm{H} / \mathrm{W}$ & Sim & $\mathrm{H} / \mathrm{W}$ \\
\hline SPWM & 4.1 & 4.6 & 3.15 & 3.6 & 2.8 & 3.2 \\
\hline SVPWM & 3.5 & 3.9 & 2.6 & 3.12 & 1.26 & 2.2 \\
\hline
\end{tabular}

provides superior performance with both SPWM and SVPWM methods.

\section{Conclusion}

A dynamic power flow control using switched Z-source converter for the hybrid renewable source associated with grid via three-phase inverter is discussed in this work. A continuous power flow is achieved by balancing the energy between source and grid using battery storage system. The THD content in the grid current is maintained well below the IEEE standard level. The results discussed above prove that the individual control of the distributed sources is possible with the proposed system. The efficient tracking of optimum power of solar, the effective control of the rectified output of the wind turbine unit to follow the optimum power and the smart control of battery energy satisfy the continuous power availability, and also a steady power is given to the grid. The system thus made gives a power that is equal to the maximum capacity of the distributed system even when the environmental condition is unfavorable and delivers stable supply even when the power from PV and wind sources is nil. Also SPWM provides fixed switching frequency and easy control methods but suffers from compact efficacy of the DC voltage at the PCC. The proposed SVPWM gives out enough DC voltage by utilizing the proper duty cycle control and minimizes the harmonic content better than SPWM scheme.

\section{References}

1. Mahmoud MS, Saif Ur Rahman M, Sunni FMAL (2015) Review of microgrid architectures - a system of systems perspective. IET Renew Power Gener 9(8):1064-1078

2. Thomson M, Infield DG (2007) Impact of widespread photovoltaics generation on distribution systems. IET Renew Power Gener $1: 33-40$

3. The Future of Energy (2012) Results Book. Bloomberg New Energy Finance (BNEF), New York

4. Bari A, Jiang J, Saad W, Jaekel A (2014) Challenges in the smart grid applications: an overview. Int J Distrib Sensor Netw 10(2):1-12

5. Fu Q, Hamidi A, Nasiri A, Bhavaraju V, Krstic SB, Theisen P (2013) The role of energy storage in a microgrid concept: examining the opportunities and promise of microgrids. IEEE Electrif Mag 1(2):21-29

6. Wei L, Joos G (2007) Comparison of energy storage system technologies and configurations in a wind farm. In: Proceedings on IEEE Power Electr. Spec. Conference, 17-21 Jun 2007, pp $1280-1285$.

7. Wang T, O'Neill D, Kamath H (2015) Dynamic control and optimization of distributed energy resources in a microgrid. IEEE Trans. Smart Grid 6(6):2884-2894

8. Wang C, Nehrir MH (2008) Power management of a stand-alone wind/photovoltaic/fuel cell energy system. IEEE Trans Energy Conv 23(3):957-967

9. Choudar A, Boukhetala D, Barkat S (2015) Brucker JM (2015) A local energy management of a hybrid PV-storage based distributed generation for micro-grids. Energy Convers Manag 90:21-33

10. Yi Z, Dong W, Etemadi AH (2018) A uni_ed control and power management scheme for PV-battery-based hybrid microgrids for both grid-connected and islanded modes. IEEE Trans Smart Grid 9(6):5975-5985

11. Balaguer IJ, Lei Q, Yang S, Supatti U, Peng FZ (2011) Control for grid-connected and intentional islanding operations of distributed power generation. IEEE Trans Ind Electron 58(1):147-157

12. Singh B (2018) Grid synchronization control for an autonomous PV-wind-battery based microgrid. In: IEEMA Engineer Infinite Conference, 2018

13. Hossain MJ, Pota HR, Mahmud MA, Aldeen M (2015) Robust control for power Sharing in microgrids with low-inertia wind and PV generators. IEEE Trans Sustain Energy 6(3):1067-1077

14. Tani A, Camara MB, Dakyo B (2015) Energy management in the decentralized generation systems based on renewable 
energy - ultra capacitors and battery to compensate the wind/ load power fluctuations. IEEE Trans Ind Appl 51(2):1817-1827

15 Liu X, Wang P, Loh PC (2011) A hybrid AC/DC microgrid and its coordination control. IEEE Trans Smart Grid 2(2):278-286

16. Zhang G, Zhang B, Li Z, Qiu D, Yang L, Halang WA (2015) A 3-Z-network boost converter. IEEE Trans Ind Electron 62(1):278-288

17. Tang Y, Wang T, He Y (2014) A switched-capacitor-based activenetwork converter with high voltage gain. IEEE Trans Power Electron 29(6):2959-2968

18. Wai RJ, Lin CY, Duan RY, Chang YR (2007) High-efficiency dc-dc converter with high voltage gain and reduced switch stress. IEEE Trans Ind Electron 54(1):354-364

19. Luo FL (2001) Six self-lift dc-dc converters. IEEE Trans Ind Electron 48(6): 1268-1272

20 Prudente M, Pfitscher LL, Emmendoerfer G, Romaneli EF, Gules R (2008) Voltage multiplier cells applied to non-isolated DC_DC converters. IEEE Trans. Power Electron. 23(2):871-887

21. Tang Y, Xie S, Zhang C (2011) An improved Z-source inverter. IEEE Trans Power Electron 26(12):3865-3868

22. Ravindranath A, Mishra SK, Joshi A (2013) Analysis and PWM control of switched boost inverter. IEEE Trans Ind Electron 60:5593-5602

23. Nguyen M, Le T, Park S, Lim Y (2015) A class of quasi-switched boost inverters. IEEE Trans Ind Electron 62:1526-1536

24. Nozadian MHB, Babaei E, Hosseini SH, Asl ES (2017) Steadystate analysis and design considerations of high voltage gain switched Z-source inverterwith continuous input current. IEEE Trans Ind Electron 64:5342-5350

25. Ahmad A, Bussa VK, Singh RK, Mahanty R (2018) Switchedboost-modified Z-source inverter topologies with improved voltage gain capability. IEEE J EmergSel Top Power Electron. 6:2227-2244

26 Mengi OO, Altaş IH (2015) A new energy management technique for PV/wind/grid renewable energy system. Int J Photo Energy. https://doi.org/10.1155/2015/356930

27. Gaurava S, Birlaa C, Lambaa A, Umashankara S, Ganesanb S (2015) Energy management of PV-battery based microgrid system. Elsevier ProcTechnol 21:103-111
28. Villalva MG, de Siqueira T, Ruppert E (2010) Voltage regulation of photovoltaic arrays: small-signal analysis and control design. Power Electron IET 3(6):869-880

29. Shi Y, Li R, Xue Y, Li H (2016) High-frequency-link-based gridtied PV system with small DC-link capacitor and low-frequency ripple-free maximum power point tracking. IEEE Trans Power Electron 31(1):328-339

30. Henze GP, Dodier RH (2003) Adaptive optimal control of a grid independent photovoltaic system. J Solar Energy Eng 125(1):34-42

31. Krishan O, Suhag S (2020) A novel control strategy for a hybrid energy storage system in a grid independent hybrid renewable energy system. Int Trans Electr Energ Syst 30:e12262. https://doi. org/10.1002/2050-7038.12262

32. Toghani Holari Y, Taher SA, Mehrasa M (2020) Distributed energy storage system-based nonlinear control strategy for hybrid microgrid power management included wind/PV units in gridconnected operation. Int Trans Electr Energ Syst 30:e12237. https ://doi.org/10.1002/2050-7038.12237

33. Lamsal D, Conradie T, Sreeram V, Mishra Y, Kumar D (2019) Fuzzy-based smoothing of fluctuations in output power from wind and photovoltaics in a hybrid power system with batteries. Int Trans Electr Energ Syst 29:e2757. https://doi.org/10.1002/ etep. 2757

34. Lopez KL, Gagne C, Gardner M-A (2019) Demand-side management using deep learning for smart charging of electric vehicles. IEEE Trans Smart Grid 10:2683-2691

35. Tirumala SV, Abhilash T, Annamalai K (2019) A seven-level VSI with a front-end cascaded three-level inverter and flying-capacitor-fed H-bridge. IEEE Trans IndAppl 55(6):6073-6088

36. Sandeep N, Yaragatti UR (2018) Design and implementation of active neutral-point-clamped nine-level reduced device count inverter: an application to grid integrated renewable energy sources. IET Power Electron 11(1112):82-91 